\title{
A Biodegradable Surface Drifter for Ocean Sampling on a Massive Scale
}

\author{
Guillaume Novelli AND CÉDRIC M. GuIGAND \\ Rosenstiel School of Marine and Atmospheric Science, University of Miami, Miami, Florida \\ CHARLes Cousin \\ Bellamare LLC, San Diego, California \\ Edward H. Ryan, NATHAn J. M. LAXAgue, HANJing DaI, \\ BRIAN K. HAUS, AND TAMAY M. ÖZGÖKMEN \\ Rosenstiel School of Marine and Atmospheric Science, University of Miami, Miami, Florida
}

(Manuscript received 23 March 2017, in final form 20 September 2017)

\begin{abstract}
Targeted observations of submesoscale currents are necessary to improve science's understanding of oceanic mixing, but these dynamics occur at spatiotemporal scales that are currently challenging to detect. Prior studies have recently shown that the submesoscale surface velocity field can be measured by tracking hundreds of surface drifters released in tight arrays. This strategy requires drifter positioning to be accurate, frequent, and to last for several weeks. However, because of the large numbers involved, drifters must be low-cost, compact, easy to handle, and also made of materials harmless to the environment. Therefore, the novel Consortium for Advanced Research on Transport of Hydrocarbon in the Environment (CARTHE) drifter was designed following these criteria to facilitate massive sampling of near-surface currents during the Lagrangian Submesoscale Experiment (LASER). The drifting characteristics were determined under a wide range of currents, waves, and wind conditions in laboratory settings. Results showed that the drifter accurately follows the currents in the upper $0.60 \mathrm{~m}$, that it presents minimal wave rectification issues, and that its wind-induced slip velocity is less than $0.5 \%$ of the neutral wind speed at $10 \mathrm{~m}$. In experiments conducted in both coastal and deep ocean conditions under wind speeds up to $10 \mathrm{~m} \mathrm{~s}^{-1}$, the trajectories of the traditional Coastal Ocean Dynamics Experiment (CODE) and the CARTHE drifters were nearly identical. Following these tests, 1100 units were produced and deployed during the LASER campaign, successfully tracking submesoscale and mesoscale features in the Gulf of Mexico. It is hoped that this drifter will enable high-density sampling near metropolitan areas subject to stress by the overpopulation, such as lakes, rivers, estuaries, and environmentally sensitive areas, such as the Arctic.
\end{abstract}

\section{Introduction}

The dispersion of surface contaminants in the ocean is driven by the variability of surface currents across spatial scales ranging from $O(1)$ to $O\left(10^{6}\right) \mathrm{m}$. To study surface transport, Lagrangian experiments are conducted by releasing tracers (a group of drifters or a cloud of dye), to analyze their trajectories and how they spread apart from each other over time (Davis 1991a; Sundermeyer and Ledwell 2001; LaCasce 2008).

The large-scale and mesoscale circulation features and their dispersion characteristics, with length scales larger

Corresponding author: Guillaume Novelli, gnovelli@rsmas. miami.edu than $O\left(10^{4}\right) \mathrm{m}$, have been extensively described using large drifter arrays (see, e.g., Davis 1991b; Zhurbas and Oh 2004; Poulain and Zambianchi 2007; Maximenko et al. 2013), such as the successful Global Drifter Program dataset that maintains 1250 Surface Velocity Program drifters at a nominal global resolution of $5^{\circ} \times 5^{\circ}$ (Lumpkin and Pazos 2007; Lumpkin et al. 2017). Submesoscale currents, with typical length scales of $10^{2}-10^{4} \mathrm{~m}$ and temporal scales of hours to days (McWilliams 2008; Thomas et al. 2008), are in theory abundant in the ocean (McWilliams 2016); however, their observation has been sporadic. In modern numerical models they play a prominent role in the ocean mixed layer (Mensa et al. 2013): first, by transferring kinetic energy from the mesoscale circulation toward the dissipative microscale (Müller et al. 2005; Poje et al. 2017); 
and second, by regulating heat and mass exchanges between the atmosphere and the ocean's pycnocline (Klein and Lapeyre 2009; D'Asaro et al. 2011; Lévy et al. 2012). Submesoscale processes induce strong surface vorticity and divergence fields (Boccaletti et al. 2007; Klein and Lapeyre 2009), which can lead floating material to form into clusters, then deform, and disperse (Huntley et al. 2015; Jacobs et al.2016). Consequently, submesoscale currents may play an important role in mixing effluent outflow from the coast and as in the transport of oil spills between the deep ocean and the shoreline. Detailed measurements of the structure of the vorticity, divergence, and strain fields described in Shcherbina et al. (2013), and the submesoscale-induced relative dispersion evidenced in Poje et al. (2014), are helpful in evaluating the accuracy of numerical models. Observations aimed to detect the existence of submesoscale flows have been sparse and at times contradictory: for instance, some studies have indicated that surface dispersion is dominated by mesoscale features in the Gulf of Mexico, in the Nordic seas, and in the Ligurian Sea (LaCasce and Ohlmann 2003; Koszalka et al. 2009; Schroeder et al. 2011), while submesoscale seemed to be the driver of relative dispersion in other studies of the North Atlantic and Mediterranean Sea (Lumpkin and Elipot 2010; Schroeder et al. 2012). Thus, the mechanisms leading to dispersion of surface material require more investigation.

Because of their spatial and temporal scales, submesoscale currents have eluded detection by means otherwise effective to describe mesoscale flows: Submesoscales are too large for synoptic measurements by fixed Eulerian arrays of moorings, and they deform too rapidly for glider transects or typical ship surveys, both subject to aliasing; they are also too small and short lived in comparison to most satellite altimetry sensors footprint, with a swath typically on the order of $7 \mathrm{~km}$ but separated by hundreds of kilometers with a repeat frequency on the order of a week (Fu and Ferrari 2008; Chavanne and Klein 2010). Occasionally, high-frequency (HF) radar systems captured submesoscale eddies, but their range is limited to coastal areas (Shay et al. 2000; Gildor et al. 2009). The visualization of the effects of submesoscale eddies and fronts is often serendipitous, revealed by the presence of oil, algae, or fish larvae, accumulating in patches and lines near the surface of the ocean (Munk et al. 2000; Jones et al. 2010; Zhong et al. 2012; Mullaney and Suthers 2013). Özgökmen et al. (2011), Özgökmen and Fischer (2012), and Özgökmen et al. (2012) conducted large-eddy simulations of idealized submesoscale features to investigate the best detection and sampling strategies for the use of Lagrangian platforms in the field. They showed that a minimum of 100-300 drifters should be released near simultaneously, with an initial separation of drifter pairs ranging from $O(0.1)$ to $O(10) \mathrm{km}$. Haza et al. (2014) demonstrated that the finite-scale Lyapunov exponent (FSLE), a scaledependent metric of two-particle dispersion, is very sensitive to the drifter position uncertainty; thus, in order to estimate relative dispersion at the submesoscale, drifter position should be reported frequently $[O(\min )]$ and with $[O(10) \mathrm{m}]$ accuracy.

The Grand Lagrangian Deployment (GLAD) was the first experiment to apply this strategy by releasing more than 300 drifters over the course of 10 days in the Gulf of Mexico in the summer of 2012. This approach successfully collected dense positions and velocity statistics from hundreds of drifter pairs and triplets across the submesoscale and mesoscale (Olascoaga et al. 2013; Poje et al. 2014; Berta et al. 2015; Curcic et al. 2016; Mariano et al. 2016; Berta et al. 2016). The operation was made possible in two ways: first, by reducing the costs, manufacturing the drifter's parts in house, following the oceanic standard Coastal Ocean Dynamics Experiment (CODE) drifter design developed in the early 1980s by Davis (1985a); second, by using off-the-shelf GPS transmitters with a low-cost data plan with the capability of reporting their position within 10-m accuracy, every $5 \mathrm{~min}$ for up to 6 months. To save space on the ship, the drifters were assembled at the last minute as needed for the deployments. GLAD data revealed an enhanced relative dispersion at the submesoscale that was previously unresolved by satellite altimetry and ocean general circulation models (OGCMs). However, GLAD did not identify the processes responsible for submesoscale flows, hence the preparation of the Lagrangian Submesoscale Experiment (LASER), which had the following objectives: (i) improve GLAD measurements with more drifter pairs and triplets in winter conditions, when the mixed layer is deeper and conducive to more energetic frontogenesis; (ii) detect specific submesoscale fronts, eddies, and filaments by mapping the velocity and density fields using a combination of drifters, ship-based measurements, and high-resolution sea surface temperature images taken from an aircraft-mounted infrared camera; and (iii) observe the evolution of these features over time with follow-up surveys and reseeding drifters over the area of interest. The experience gained from GLAD made it clear that several issues had to be addressed for future large drifter deployments. First, to capture several realizations of submesoscale events with appropriate spatiotemporal resolution, the LASER campaign would require more drifters-at least 1000 units. Second, the drifter must represent the transport because of nearsurface currents, which means its wind-induced drift must be quantified. Third, a new drifter design is needed: it should be mass produced to reduce the labor and cost per 
unit. It must also be compact for transportation, as well as easily and rapidly assembled. Fourth, considering both the persistence and the toxicity of petroleum-based plastics in the marine environment (Moore 2008; Gregory 2009; Cózar et al. 2014; Wilcox et al. 2015), most of the drifter parts should be biodegradable to avoid throwing tons of harmful material into the ocean.

In this paper we present a new biodegradable surface drifter, named after the Consortium for Advanced Research on Transport of Hydrocarbon in the Environment (CARTHE), that is specifically developed to facilitate high-resolution sampling of the ocean surface velocity field without aliasing errors that are inherent in non-Lagrangian platforms. The design is presented in section 2 . The drifter body is made by injection molding of a nontoxic biopolymer that will resist structurally for the duration of the experiment and will be entirely degraded by bacteria in 5 years (in contrast to hundreds of years for traditional plastics) if left in the marine environment or in the soil. The drifter is made of only four parts, efficiently stored and assembled. It contains a GPS device similar to that of GLAD, chosen for its low cost, accuracy, and data plan of frequent position reports. The next two sections are devoted to establishing the drifting characteristics of the drifter: First, experiments conducted in a tank showed that the drifter accurately follows the Lagrangian near-surface currents, even under steep waves and strong surface winds (section 3). Second, coastal (section 4) and deep (section 5) ocean experiments showed that the CARTHE drifter and the CODE drifter, deployed side by side, have nearly identical trajectories. The deployment of more than 1000 of these drifters in the LASER expedition is described in section 6. Finally, conclusions follow in section 7 .

\section{Description of the drifter}

\section{a. GPS-tracking component}

An off-the-shelf, mass-produced GPS tracker (Spot Trace by Globalstar) was chosen because of its adequate coverage of the Gulf of Mexico for LASER, and for its low-cost flat-rate yearly communication fee. It has a compact circuit board with a mass of $0.020 \mathrm{~kg}$ and dimensions of $55 \mathrm{~mm} \times 45 \mathrm{~mm} \times 5 \mathrm{~mm}$. The Spot Trace can transmit its position every $5 \mathrm{~min}$ through a simplex data modem using the low-orbiting Globalstar satellite constellation. Using three D-cell alkaline batteries, with a mass of $0.580 \mathrm{~kg}$, the power lifetime of the GPS averages 60 days reporting its position every $5 \mathrm{~min}$. The position accuracy was determined by comparing the positions reported by several GPS units placed on the roof of a building for 2 weeks. The cumulative histogram of the position accuracy is shown in Fig. 1: $95 \%$ of the positions have an error of $10 \mathrm{~m}$ or less.

\section{b. Material and design}

Instruments deployed in the ocean have to be made to withstand corrosion and mechanical fatigue. Drifters are no exception. For instance, the Surface Velocity Program (SVP) drifters, used in the Global Drifter Program run by NOAA, have a half-life of about 450 days (Lumpkin and Pazos 2007; Lumpkin et al. 2017), which is ideal for the large climatic-scale measurements for which they are used. But even drifters developed for short-term, regional-scale studies aim for longevityand cost efficiency-like the Microstar drifter developed by Pacific Gyre (Ohlmann et al. 2005), by using hydrocarbon-based plastics in their diverse forms [e.g., epoxy resins, nylon, or polyvinyl chloride (PVC)]. Plastics are ubiquitous and economical in manufacturing because of their versatility, strength, and resilience. But they also have a very low biodegradability and may stay in the marine environment for hundreds of years (Law 2010; GESAMP 2015; Andrady 2015). For this reason, we looked for a material alternative to plastic that would guarantee the structural integrity of the instruments and quality measurements for as long as the batteries would last, without becoming a threat to the environment afterward. This would allow researchers to sample more degrees of freedom in the ocean by deploying more sacrificial drifters without polluting.

Our first approach was to create a wooden drifter made from simple interlocking parts. Preliminary designs were made of bamboo or regular birch plywood, with a top buoyancy disc (or ring) made either of wood, aluminum tubing, or even cork, as can be seen in Fig. 2. The GPS and batteries would go in a small waterproof box mounted on top of the buoyancy element. The drifter was held upright by a keel made of steel angles, to lower the center of gravity well below the center of buoyancy. But wood, if not treated to avoid toxicity, absorbs water over time, and the drifter would sink below the surface level by the weight of the steel keel within 2 weeks.

A major design review followed as the existence of polyhydroxyalkanoates (PHA) came to light. PHA are a class of biopolymers made from renewable carbon instead of fossil fuels: they are extracted from the fermentation of corn sugar. They also meet the ASTM International standard for biodegradability in the marine environment (Reddy et al. 2003; DiGregorio 2009). We choose to use Mirel PHA products from Metabolix Inc. (Cambridge, Massachusetts), which do not absorb water, yet were verified to completely biodegrade in seawater and sediments, at a rate of $0.1 \mathrm{~mm} \mathrm{month}^{-1}$ 


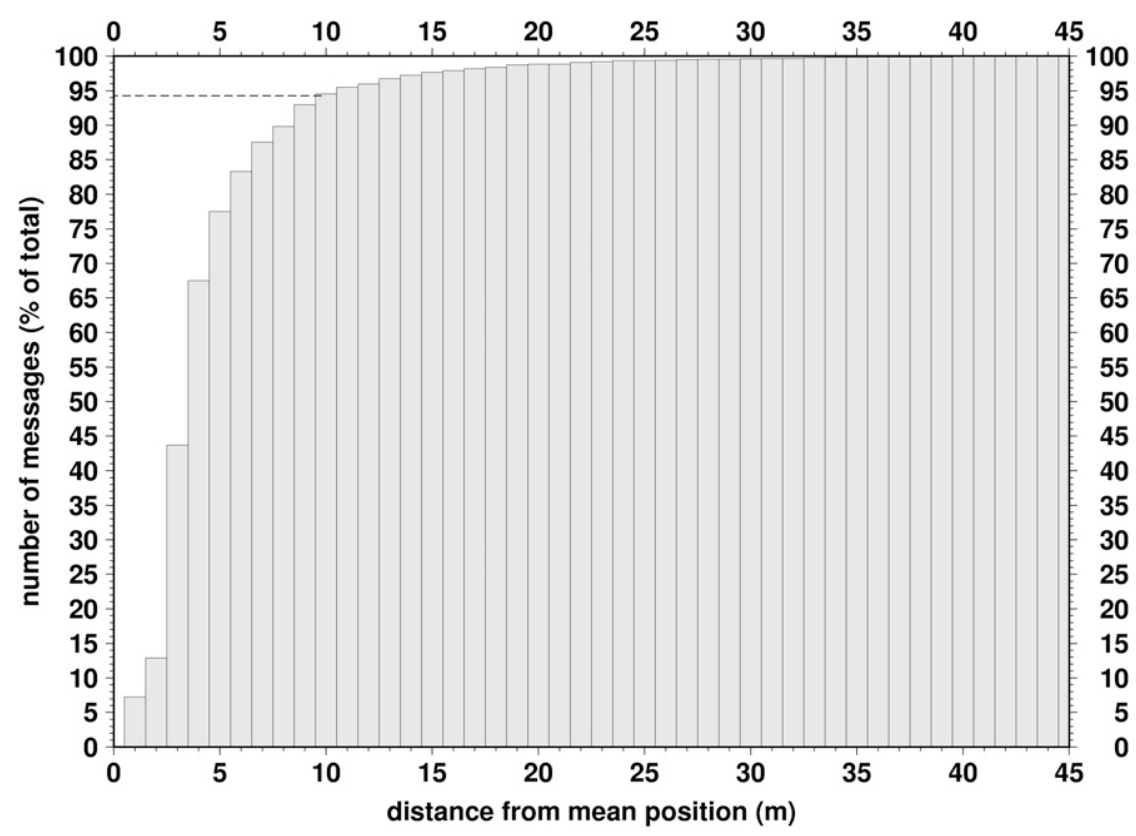

FIG. 1. GPS position accuracy test: Cumulative histogram of the number of messages as a function of the distance to the mean position. The 95th percentile is denoted (dashed line), showing that $95 \%$ of the positions have an error of $10 \mathrm{~m}$ or less.

under standardized tests done by independent certification organizations such as the Biodegradable Products Institute and Vinçotte. PHA are thermoplastics that have the required qualities for industrial injection molding as well, thus facilitating the production of several hundred parts per week.

The design improved in several steps. First, scale models were produced by $3 \mathrm{D}$ printing. Next, the scale models were tested in a wind-wave-current flume where the drifter's motion can be carefully analyzed under steep waves and strong winds (up to $23 \mathrm{~m} \mathrm{~s}^{-1}$ ). Designs that did not follow the current accurately in the presence of waves or wind were modified until a satisfactory Lagrangian behavior was obtained. Then, full-scale models were tested in the ocean. We compared their trajectories to those of CODE drifter, considered as an accurate representation of the Lagrangian current over the upper meter (Davis 1985a; Poulain 1999). The study of the drifter's dynamics is presented in detail in sections 3 and 4.

The end result of this process is the CARTHE drifter design presented in Fig. 3. It is composed of four parts
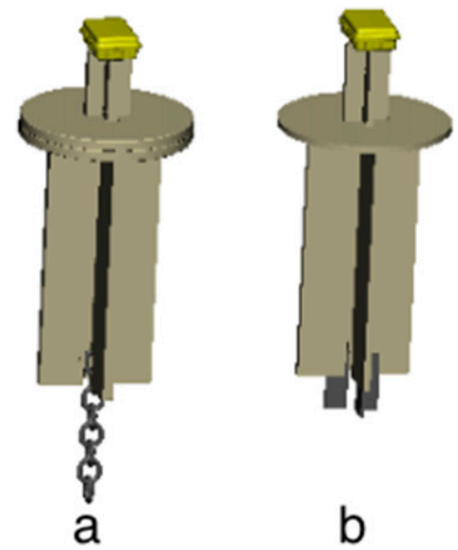

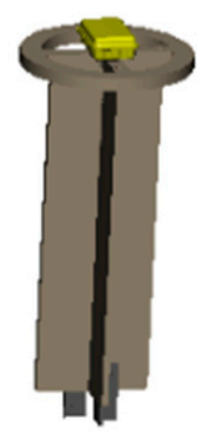

C

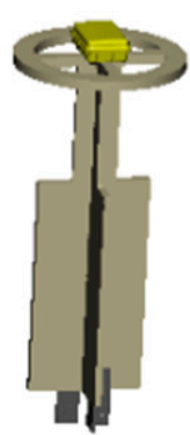

d

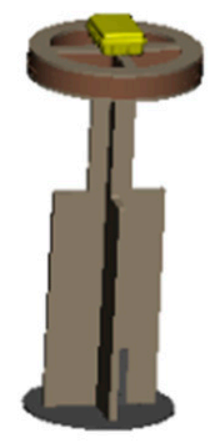

e

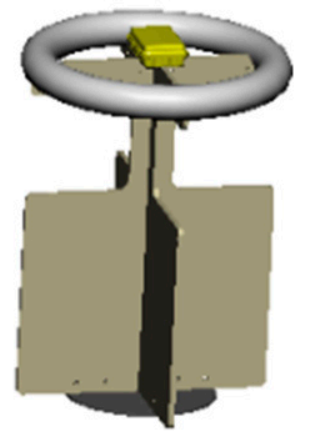

f

FIG. 2. Initial designs using a plywood drifter body with a float made of (a)-(d) plywood, (e) cork, and (f) eventually an aluminum torus. (a) Chain, (b)-(d) metal angles, and (e),(f) metal plates were used to create a keel for these wooden designs. The yellow box represents the waterproof GPS and battery compartment. 


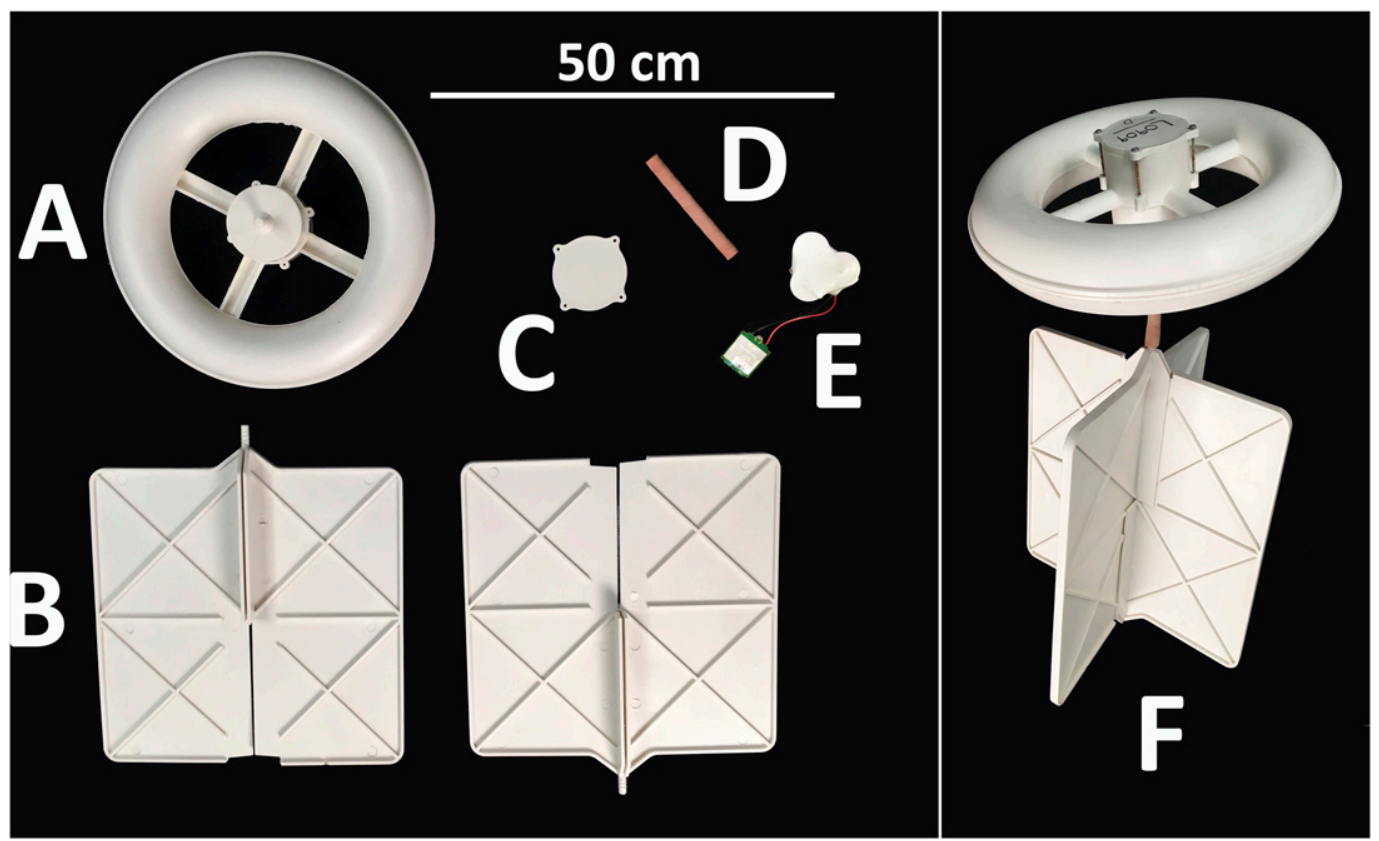

FIG. 3. The CARTHE drifter parts: (a) toroidal float with GPS housing in the center, (b) interlocking drogue panels, (c) GPS housing lid, (d) flexible rubber tether, (e) GPS board and battery pack, and (f) drifter fully assembled and ready for deployment.

made of PHA and manufactured by injection molding: the torus float with an integrated GPS/battery compartment in its center (A in Fig. 3), the two interlocking drogue panels (B in Fig. 3), the lid to close the GPS enclosure ( $\mathrm{C}$ in Fig. 3), and a flexible rubber tether link (D in Fig. 3), as well as the battery and GPS tracker unit (E in Fig. 3). The drogue panels' dimensions are $0.38 \mathrm{~m} \times$ $0.38 \mathrm{~m}$. They are connected to the floater via a $0.15-\mathrm{m}$ natural rubber tubing tether. The torus outside diameter is $0.38 \mathrm{~m}$. Thus, the drifter design aims to represent the horizontal transport of a cylindrical volume of water of $0.38 \mathrm{~m}$ in diameter and extends vertically from the surface down to $0.60-\mathrm{m}$ depth, with the drogue centered at a depth of $0.40 \mathrm{~m}$. The overall mass of a fully assembled drifter ( $F$ in Fig. 3 ) is $4 \mathrm{~kg}$. The flexible natural rubber tubing that links the drogue and the floater allows the drifter to follow accurately the motion of the free surface and to stay in phase with the waves (see section 3). The torus shape of the floater presents a smooth and aerodynamic profile to surface winds: the torus has less than $0.03 \mathrm{~m}$ protruding out of the water for a volume of $2.8 \mathrm{~L}$. For comparison, a spheric float of the same volume would have a radius of $0.088 \mathrm{~cm}$; thus, it would be more subject to wind. The parts can be stored efficiently and assembled in minutes, which makes handling the drifter quite practical on the deck of a ship.

All the materials used in the drifter were selected to reduce as much as possible the environmental harm posed by large deployments when drifters cannot be collected immediately after the experiment: the drifter body (floater and drogue) is made of biodegradable PHA; the fasteners are made of steel (not stainless steel), so they eventually rust away in the ocean; the tether tubing is made of natural rubber; the modern alkaline battery packs do not contain lead nor mercury and are not classified as hazardous waste by the U.S. Environmental Protection Agency (EPA): since 1993, alkaline batteries pass the toxicity characteristic leaching procedure (TCLP) test,which determines whether a material degrades into substances hazardous for humans and the environment; the Spot Trace GPS board is compliant with the stringent European restriction of hazardous substances directive (RoHS), which prohibits the use of substances known to be harmful to humans and animals (lead, mercury, cadmium, hexavalent chromium, polybrominated biphenyls, polybrominated diphenyl ethers, Bis(2-Ethylhexyl) phthalate, benzyl butyl phthalate, dibutyl phthalate, diisobutyl phthalate). The CARTHE drifter is $85 \%$ biodegradable material and $15 \%$ nontoxic electronics in its composition. Every material and component integrated into the CARTHE drifter were selected in order to minimize, with the current technology, the mass of potentially harmful waste added to the ocean during drifter experiments.

Drifter data can be useful only if the drift characteristics are known. To evaluate the water-following 
capabilities of the CARTHE drifter, a twofold approach was pursued: (i) in a wind-wave-current flume, the slip velocity of the drifter was measured with respect to the Lagrangian velocity of a variety of controlled flows (see section 3); (ii) in the ocean, the behavior of the CARTHE drifter was compared to the behavior of the well-established CODE drifter design, by deploying both drifters in the same flow (see section 4).

\section{Laboratory study of drifter's dynamics}

\section{a. Material and methods}

\section{1) WIND-WAVE FLUME}

Laboratory observations were made at the Air-Sea Interaction Saltwater Tank (ASIST; Fig. 4) at the University of Miami's Surge Structure Atmosphere Interaction (SUSTAIN) facility, which offers the possibility to control the flow via a water pump, a paddle wave maker, and a wind generator. The acrylic flume is $15 \mathrm{~m}$ long, with a $1 \mathrm{~m} \times 1 \mathrm{~m}$ cross section, and a mean water depth set to $0.43 \mathrm{~m}$. A permeable wave-absorbing sloped beach was installed at the downwind end. The sampling window is a $1.60-\mathrm{m}$-long section of the flume, located at equal distance $(\sim 6 \mathrm{~m})$ from the inlet and the outlet of the flume to minimize any boundary effects. The wind speed in the tunnel was monitored by a sonic anemometer located in the sampling window, $0.285 \mathrm{~m}$ above the mean water level (labeled A in Fig. 4). Two wave gauges (partially submerged conductivity probes) were installed at two different locations in the sampling window to make sure the wave field was homogeneous in the measurement area (labeled $\mathrm{C}$ in Fig. 4). They recorded water surface elevation time series $[\eta(t)]$ at a sampling rate of $100 \mathrm{~Hz}$.

\section{2) Current measurements}

The goal is to compare the drifter's velocity to the Lagrangian velocity of a fluid element of the same volume as the drifter. Subsurface Eulerian current profiles $U_{E}(z)$ were measured by particle image velocimetry (PIV). Wave-induced Stokes drift profiles $U_{S}(z)$ were derived from the surface elevation time series. The sum of the Eulerian and Stokes drift components is the Lagrangian velocity $U_{L}$, where $U_{L}=U_{E}+U_{S}$. The velocity of the upper $1 \mathrm{~cm}$ was measured by tracking a cloud of surface-released dye with a side-mounted camera.

\section{(i) PIV}

The PIV pulsed laser sheet/camera system was set up to measure the vertical profiles of the along-tank

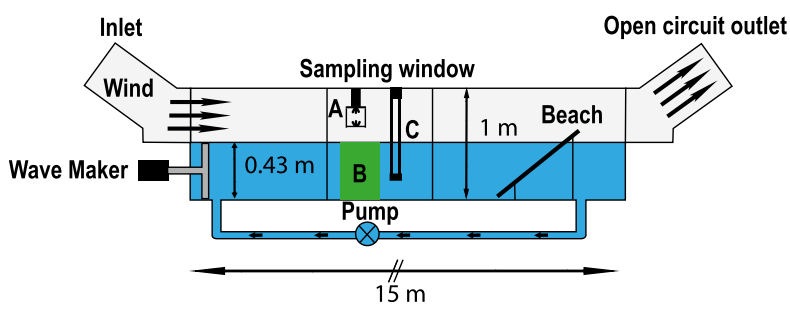

FIG. 4. Sketch of the ASIST wind-wave-current flume, including the positions of the instruments monitoring the flow in the sampling window: (a) sonic anemometer, (b) PIV measurements area, and (c) wave gauges.

velocity component (blue rectangle B in Fig. 4). Polyamide seeding particle beads of $50-\mu \mathrm{m}$ diameter and 1.06 specific gravity were used as passive scatterers. Each measurement was repeated five times, acquiring at $15 \mathrm{~Hz} 50$ pairs of images separated by $2 \mathrm{~ms}$. The images were processed using an adaptive correlation technique and the resulting velocity vector fields were horizontally averaged over a $1-\mathrm{cm}$-wide region of interest to produce robust velocity profiles with $5-\mathrm{mm}$ resolution in the vertical. The resulting profiles extend from the bottom of the tank up to $5 \mathrm{~cm}$ below the free surface, depending on the wave height. It was not possible to retrieve the velocity profiles near the surface, above the depth of approximately twice the amplitude of the dominant wave. The mean Eulerian current $U_{E 0}$ depth-averaged over the drifter draft $z_{d}$, is defined as

$$
U_{E 0}=\frac{1}{\left|z_{d}\right|} \int_{0}^{z_{d}} U_{E}(z) d z
$$

\section{(ii) Near-surface dye tracking}

Food-dye droplets, released just above the free surface, were filmed at 30 frames per second by a camera mounted on the side of the tank and looking slightly upward. The colored water patch would rapidly expand according to the near-surface shear induced by the presence of waves or wind: the leading edge of the dye was located at the surface, while the deepest fractions trailed (see Fig. 5). The velocity of the water in the uppermost centimeter is obtained by tracking the leading edge of the dye in each frame as it crosses the sampling area. These measurements were repeated 10 times for each wind speed considered.

Near-surface Lagrangian velocity profiles (later deno-

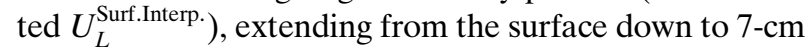
depth, were interpolated finding the best fitting (in a least squares sense) third-order polynomial function passing through the uppermost eight points of the PIV measurements and the surface dye velocity. 

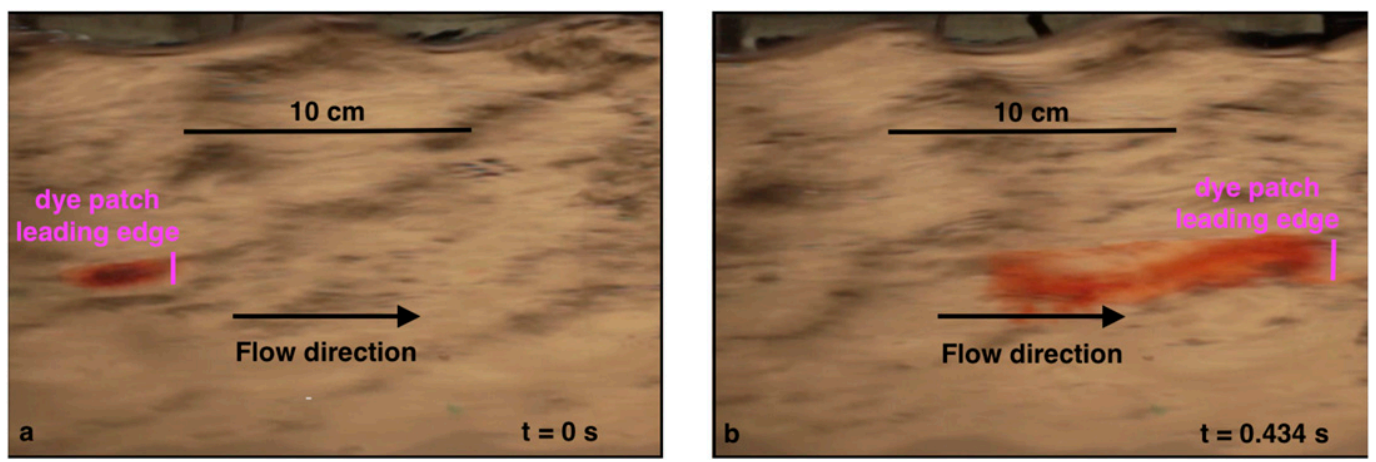

FIG. 5. Two sequential images of camera-tracked dye patch position under $U_{10}=11.6 \mathrm{~m} \mathrm{~s}^{-1}$ and imposed background current $U_{E 0}=0.12 \mathrm{~m} \mathrm{~s}^{-1}$. The magenta line shows the position of the leading edge of the surface dye. Time separation between these two images is $0.434 \mathrm{~s}$.

\section{(iii) Stokes drift}

Gravity waves contribute to the transport velocity of a flow via the Stokes drift (Stokes 1847). For a simple monochromatic wave, such as the one generated by the paddle of the ASIST wave maker, Phillips (1977) derived the following expression of the Stokes drift profile:

$$
U_{S}(z)=\omega k a^{2} \frac{\cosh [2 k(D+z)]}{2 \sinh (k D)^{2}},
$$

where $a$ is the amplitude of the wave, $\omega=2 \pi f$ is the absolute angular frequency, $k$ is the wavenumber, and $D$ is the mean water depth $(D=0.43 \mathrm{~m})$. The bulk wave parameters, such as the imposed wave frequency $f$ and the significant wave height $H_{s}=4 \sigma_{\eta}=2 a$ [where $\sigma_{\eta}$ is the standard deviation of $\eta(t)$ ], can be readily estimated from $\eta(t)$. The wavenumber $k$ is obtained by resolving iteratively the wave dispersion relation using

$$
\left(\omega-k U_{E 0}\right)^{2}=g k \tanh k D,
$$

where $U_{E 0}$ is the mean background current, like the one imposed by the water pump.

One can see from Eq. (2) that the Stokes drift is maximal at the surface $(z=0)$ and decays exponentially with depth. Stokes drift increases with wave steepness $k a$, the product of the wave height, and the wavenumber (or ratio of wave height over wavelength).

When waves grow as a result of wind stress applied at the air-sea interface, a continuous spectrum of waves is generated. In the ASIST flume, $\eta(t)$ recorded by the wave gauges is converted to a wave frequency spectrum $S_{f}(f)$ by applying a Fourier transform to $\eta(t)$. In Webb and Fox-Kemper (2011, 2015), a formulation was introduced to estimate the one-dimensional Stokes drift by integrating the third moment of the frequency spectrum as follows:

$$
U_{S}(z)=\frac{16 \pi^{3}}{g} \int_{0}^{\infty} f^{3} S_{f}(f) e^{\frac{8 \pi^{2} f^{2}}{g}} \mathrm{~d} f
$$

where $g=9.81 \mathrm{~m} \mathrm{~s}^{-2}$ is the gravitational acceleration.

\section{3) DRIFTERS}

Laboratory tests were the only way to safely and fully observe the drifter's reaction, particularly under strong winds $\left(U_{10} \geq 20 \mathrm{~m} \mathrm{~s}^{-1}\right)$ and steep waves. However, the real drifter is too large for the available depth and width of the channel; therefore, exact half-scale replicas were 3D printed out of PLA plastic. This technique ensures that each replica has the same mechanical and hydrodynamic properties as the real size drifter. Small weights were added to the drifter inside the float enclosure to simulate the presence of a half-sized battery and GPS package, and to account for the difference in density between the PLA and the Mirel plastics (1.25 and $1.35 \mathrm{~g} \mathrm{~cm}^{-3}$, respectively).

We investigated the different responses to wind and wave conditions of three designs, labeled $\mathrm{A}, \mathrm{B}$, and $\mathrm{C}$, respectively, in Fig. 6:

A. CARTHE drifter: an exact half-scale replica of the CARTHE drifter, with a toroidal float containing one-eighth of the weight of the batteries and a GPS in its enclosure, and a $0.075-\mathrm{m}$ flexible rubber tether connected to the interlocked drogue panels reaching a draft $z_{d}=-0.30 \mathrm{~m}$.

B. Rigid neck drifter: an altered CARTHE drifter where the tether is made rigid by inserting a threaded metallic rod inside the flexible rubber tube and screwing it into both the float and the drogue.

C. Floater: without a drogue and a tether, is a halfscale replica of the CARTHE drifter float. Its draft is $z_{f}=-0.03 \mathrm{~m}$.

For each of the flow conditions described next, 10 measurements were made of the time needed for each 


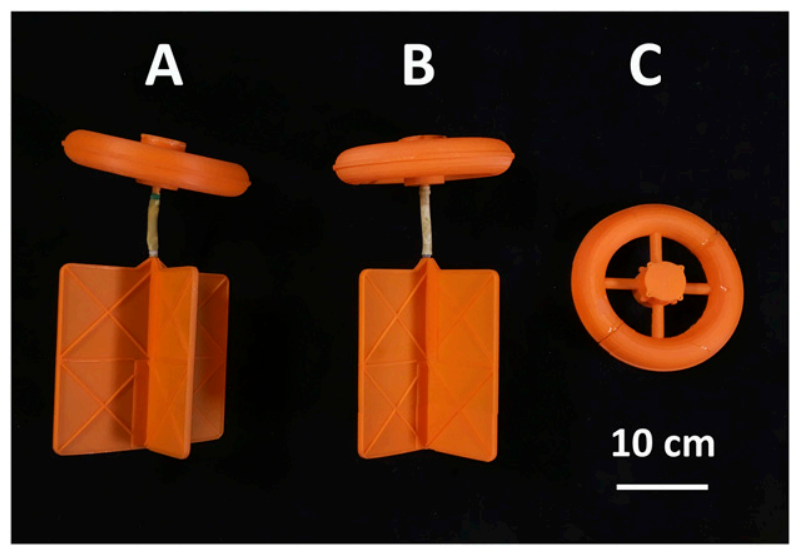

FIG. 6. 3D printed half-scale drifters tested in the ASIST flume:

(a) CARTHE drifter, (b) rigid neck drifter, and (c) floater.

drifter to cross the sampling window. This defined the drifter's mean speed, and standard deviation, for each condition.

\section{4) Current, Wind, AND WAVE CONDITIONS}

As pointed out in previous works on surface and mixed-layer drifter designs (Davis 1985a; Niller et al. 1987; Geyer 1989; Niiler et al. 1995), there are four causes for a drifter to slip through the current: 1) the wind drag on the dry area of the drifter; 2) the wave rectification, which is the added velocity induced by the passage of waves through a drifter; 3 ) the vertical shear of the velocity field over the draft of the drifter; and 4) the current drag on the tether and the wet area of the float. Thus, three experiments were set up in which the three different types of drifter were submitted to the same flows in order to isolate and measure the effects of wave rectification and windage on the drifters' speeds.

\section{(i) Experiment 1: Steady currents}

In the first test the drifters were released into a steady current in order to establish a baseline. The water velocity profiles were measured for six flow rates. Table 1 lists the depth-averaged flow velocities $U_{E 0}$ measured in each trial. The profiles will be compared with the next cases, where vertical shear was introduced by adding waves and wind on top of the background flow.

(ii) Experiment 2: Short and steep monochromatic waves over a mean current

To isolate spurious drifter motions caused by waves from other causes of slip, such as wind drag, experiment 2 was carried out without wind. The background current was kept constant at $U_{E 0}=0.06 \mathrm{~m} \mathrm{~s}^{-1}$, while a monochromatic wave was imposed via the wave-maker paddle. The horizontal Lagrangian velocity of the flow,
TABLE 1. Experiment 1: Velocity of the imposed background current depth averaged over the drifter's draft.

\begin{tabular}{lllllll}
\hline \hline$U_{E 0}\left(\mathrm{~m} \mathrm{~s}^{-1}\right)$ & 0.06 & 0.08 & 0.12 & 0.16 & 0.18 & 0.20 \\
\hline
\end{tabular}

that a drifter should match, results from only two components: the background current and the wave-induced Stokes drift.

The response of half-scale drifters to waves was investigated for frequencies ranging from 0.0 and $4.0 \mathrm{~Hz}$. The measurements presented here focus only on frequencies at or near $1.5 \mathrm{~Hz}$, when the rigid neck drifter moved much faster than the flow as a function of $k a$. For higher and lower frequencies, the drifter did not show an anomalous response. Table 2 summarizes the imposed wave frequencies and amplitudes corresponding to a steepness varying between 0.03 and 0.19 .

\section{(iii) Experiment 3: Winds over a mean current}

In the third experiment, the background current was set to $U_{E 0}=0.12 \mathrm{~m} \mathrm{~s}^{-1}$, while five different wind speeds were imposed successively in order to estimate the relationship between wind speed and wind-induced drifter's slip velocity (the difference between the drifter's velocity and the flow velocity). The waves were allowed to grow until saturation before the drifters' velocities and velocity profiles were measured. Table 3 contains the imposed wind speed $V$, measured $0.285 \mathrm{~m}$ above the mean water level, and the respective equivalent neutral wind speed $U_{10}$ [scaled via the bulk algorithm of Smith (1988)]. The wind-wave frequency spectra $S_{f}(f)$, relative to the wind conditions of experiment 3 shown in Fig. 7, show that as the wind speed increases, the wave energy increases and is distributed in higher-frequency waves. It will be shown in the coming results section that, compared to the monochromatic waves of the previous experiment, these waves have a more intense surface Stokes drift velocity but that the Stokes drift profile also decays faster with depth.

\section{b. Laboratory results}

\section{1) EXPERIMENT 1: DRIFTERS IN STEADY CURRENTS}

The drifters' velocities and water velocity profiles $\overline{U(z)}$ are shown in Fig. 8. Lagrangian and Eulerian velocities are equal $\left[\overline{U(z)}=U_{E}(z)=U_{L}(z)\right]$, because of the absence of waves and Stokes drift. The current is vertically uniform in the upper $0.30 \mathrm{~m}$ of the profile, which the drifters sample, with a bottom boundary layer extending about $0.04 \mathrm{~m}$ from the bottom. 
TABLE 2. Experiment 2: Frequency, amplitude, and steepness of the imposed monochromatic waves.

\begin{tabular}{llllll}
\hline \hline$f(\mathrm{~Hz})$ & 1.25 & 1.25 & 1.50 & 1.50 & 1.50 \\
$a(\mathrm{~cm})$ & 0.45 & 1.00 & 1.24 & 1.82 & 2.33 \\
$k a$ & 0.03 & 0.06 & 0.10 & 0.15 & 0.19 \\
\hline
\end{tabular}

The error bars around the drifter mean velocity values represent one standard deviation about the mean. The floater has larger variability because of its lack of drogue, and it tends to slip more and cross the sampling window in diagonal depending on its exact initial release location and velocity.

Figure 9 shows that the average drifter velocities $U$ agree well with $U_{E 0}$. This is true for the three drifter designs tested: the CARTHE drifter gives the current velocity within $0.01 \mathrm{~m} \mathrm{~s}^{-1}$, while the floater's velocity is within $0.02 \mathrm{~m} \mathrm{~s}^{-1}$.

\section{2) EXPERIMENT 2: DRIFTERS' INTERACTION WITH SHORT AND STEEP WAVES}

The velocities in the tank for different waves are shown in Fig. 10, color coded by ka. The floater and the rigid neck drifter velocities are seen to increase in similar fashion, up to $1.5 U_{E 0}$, with wave steepness. However, the CARTHE drifter remains approximately at the same velocity on the order of the imposed background velocity $U_{E 0}$.

The Stokes drift $U_{S}(z)$, shown with dashed lines in Fig. 10 [computed using Eq. (2) in Phillips 1977], increases significantly with the wave steepness, from $U_{S}(z=0)=0$ for $k a=0$ to $U_{S}(z=0)=0.66$ $U_{E 0}=0.04 \mathrm{~ms}^{-1}$ for $k a=0.19$. The Stokes drift is negligible below $0.20-\mathrm{m}$ depth.

The Stokes drift induced by the waves is compensated by a sharp decrease of $U_{E}(z)$, with lines of small circles, with respect to the velocity profile in the absence of waves (solid gray line), especially noticeable for the steepest wave at $k a=0.19$.

The resulting Lagrangian velocity profiles $U_{L}(z)=$ $U_{E}(z)+U_{S}(z)$, indicated with dashed-dotted lines, show a strong vertical shear in the surface boundary layer: the fluid elements located within a depth of twice the amplitude of the wave $(-2 a \leq z<0)$ are subject to an intense Stokes drift. Stokes drift diminishes rapidly with depth. The near-surface $(-2 a \leq z<0)$ Lagrangian

TABLE 3. Experiment 3: Wind speed measured at $0.285 \mathrm{~m}$ above the mean water level and its equivalent at $10 \mathrm{~m}$.

\begin{tabular}{lrrrrr}
\hline \hline Wind speed at $0.285 \mathrm{~m} \mathrm{~V}\left(\mathrm{~m} \mathrm{~s}^{-1}\right)$ & 5.7 & 7.8 & 9.8 & 11.9 & 14.0 \\
$U_{10}\left(\mathrm{~m} \mathrm{~s}^{-1}\right)$ & 8.2 & 11.6 & 15.2 & 19.0 & 23.0 \\
\hline
\end{tabular}

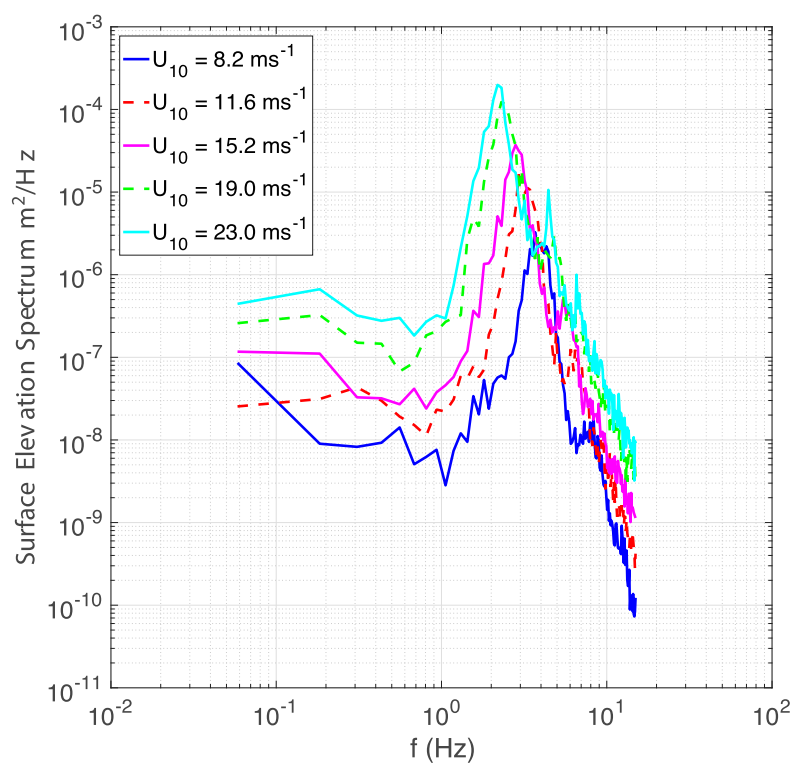

FIG. 7. Surface elevation frequency spectra $S_{f}(f)$ as a function of wind speed.

velocity profiles were estimated by best fitting a thirdorder polynomial function between the floater velocity and the uppermost eight Lagrangian velocity measurements [sum of the PIV measurements $U_{E}(z<-2 a)$ and the respective Stokes drift values $U_{S}(z<-2 a)$ ] for each wave. The drifters' velocities can then be compared to the Lagrangian velocity integrated over the floater's draft $\left(z_{f}=-0.03 \mathrm{~m}\right)$, defined by

$$
\left\langle U_{L}\right\rangle_{\left[0, Z_{f}\right]}=\frac{1}{\left|z_{f}\right|} \int_{0}^{z_{f}} U_{L}(z) d z
$$

and over the CARTHE drifter's draft $\left(z_{d}=-0.30 \mathrm{~m}\right)$, defined as

$$
\left\langle U_{L}\right\rangle_{\left[0, z_{f}\right]}=\frac{1}{\left|z_{d}\right|} \int_{0}^{z_{d}} U_{L}(z) d z
$$

which is done in Fig. 11.

In Fig. 11 all velocities have been scaled by the background velocity $U_{E 0}$. According to Monismith et al. (2007), who compiled observations from a number of wave flumes worldwide, the Lagrangian velocity in wave flumes appears to be constant and equal to the background current, independently from the wave that is imposed. If this holds true in the ASIST flume, then $\left\langle U_{L}\right\rangle_{\left[0, z_{d}\right]}=U_{E 0}$ is expected. Our results show effectively that the Lagrangian velocity $\left\langle U_{L}\right\rangle_{\left[0, z_{d}\right]}$, with lines of small circles, remains between $0.8 U_{E 0}$ and $1.0 U_{E 0}$.

The effect of the wave rectification on the rigid neck drifter is remarkable: the rigid neck drifter velocity increases significantly with wave steepness, up to $1.5 U_{E 0}$. 


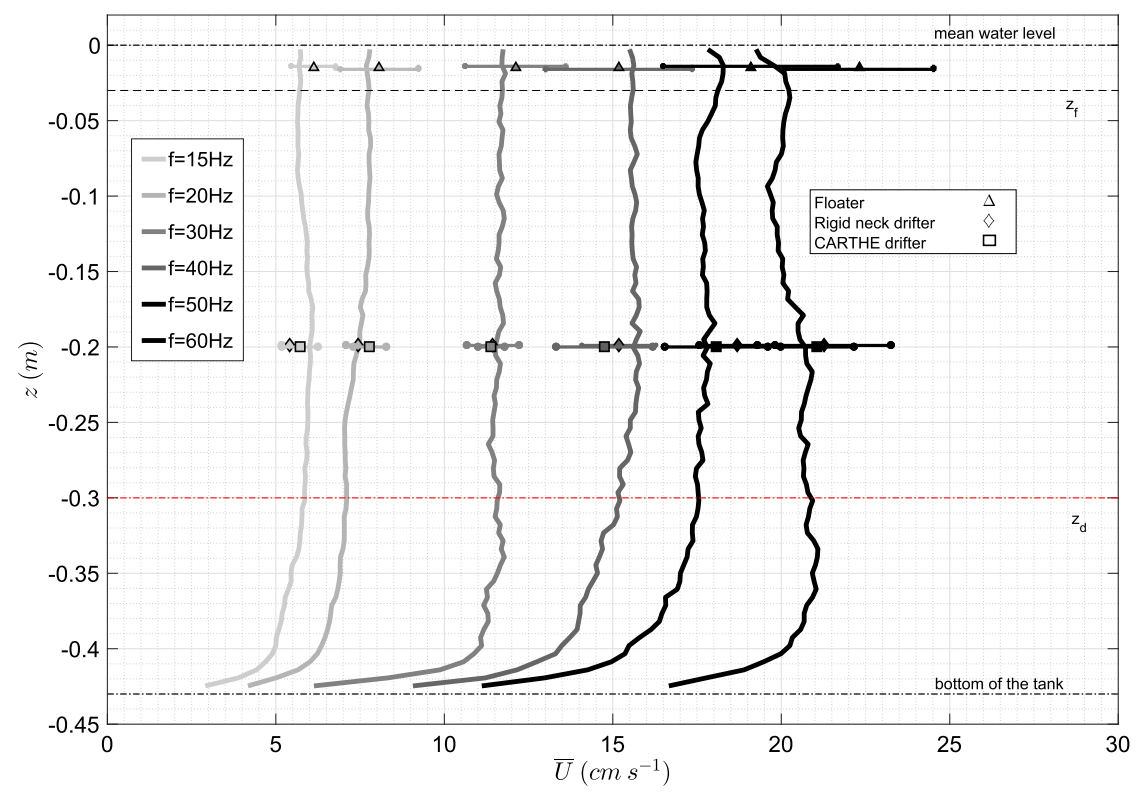

FIG. 8. Experiment 1: Velocities in the tank for increasing water pump frequencies $f$. Velocity profiles $U_{E}(z)$ retrieved by PIV (gray lines). The symbols $(\triangle, \diamond$, and $\square$ ) are the drifters' speed (floater, rigid neck, and CARTHE, respectively), and the error bars represent one standard deviation about the mean. Also indicated by dashed and dash-dotted lines are: at $z=0 \mathrm{~m}$, the mean water level; at $z_{f}=-0.03 \mathrm{~m}$, the bottom of the floater; at $z_{d}=-0.30 \mathrm{~m}$, the bottom of the drifter drogue; and at $z=-0.43 \mathrm{~m}$, the bottom of the tank.

The drifter acts as an oscillator that enters in resonance with waves of a specific frequency of $1.5 \mathrm{~Hz}$. The wavenumber $k$ associated is about $k=8$, corresponding to a wavelength of $\lambda=0.8 \mathrm{~m}$, or about 4 times the drifter diameter. To resolve this issue, the flexible tether was implemented successfully in the CARTHE drifter design to decouple the motion of the floater from the drogue: the velocity of the CARTHE drifter is independent of wave steepness, always between $0.9 U_{E 0}$ and $1.1 U_{E 0}$. There is no more resonant interaction of the drifter with the waves.

In Davis (1985a), the wave rectification motions of two unsuccessful drifter designs were described only qualitatively. In this experiment, the rectification of the rigid neck drifter in short steep waves was observed and precisely measured as a function of wave steepness. The net transport of the drifter was found to be in the direction of wave propagation, up to $50 \%$ faster than the velocity of the volume of water it should represent. The experiment demonstrated as well that using a flexible tether in the CARTHE drifter was essential to reduce wave rectification and to obtain a good nearsurface current follower in the presence of short steep waves. The wave frequency that led to a resonant response of the drifter corresponds to wavelengths about 4 times the drifter's diameter. In the real ocean, equivalent wavelengths would be about $1.6 \mathrm{~m}$, with frequencies on the order of $1 \mathrm{~Hz}$. Such waves are forced by the wind and are common in all oceans at any time the wind is blowing.

\section{3) EXPERIMENT 3: DETERMINATION OF THE WIND-INDUCED DRIFTERS' SLIP VELOCITY}

The velocities in the tank for different wind speeds are shown in Fig. 12, color coded by $U_{10}$. The near-surface dye's Lagrangian velocity increases sevenfold when the neutral wind speed increases from $U_{10}=0 \mathrm{~m} \mathrm{~s}^{-1}$ to $U_{10}=23 \mathrm{~m} \mathrm{~s}^{-1}$. The floater's velocity increases 4.5 times at the maximum wind speed. Comparatively, the rigid neck and the CARTHE drifters' velocities increase by a factor of 1.4 .

The Stokes drift profiles $U_{S}(z)$, denoted with colored dashed lines, are significantly intensified near the surface, reaching up to $U_{S}(z=0)=0.1 \mathrm{~m} \mathrm{~s}^{-1}=O\left(U_{E 0}\right)$, and decay rapidly under $0.01 \mathrm{~m} \mathrm{~s}^{-1}$ at $z \leq-0.04 \mathrm{~m}$. Consequently, Stokes drift contributes to the Lagrangian velocity only in the uppermost $0.04 \mathrm{~m}$ below the mean water level: for $z \leq-0.04, U_{L}(z)=U_{E}(z)$. The Eulerian velocity profiles $U_{E}(z)$ are plotted in colored circles. The near-surface Lagrangian velocity profiles, denoted with colored dashed-dotted lines, were estimated by best fitting a third-order polynomial function between the uppermost eight PIV measurements $U_{E}(z<2 a)$ and the surface dye's velocity for each wind speed. 


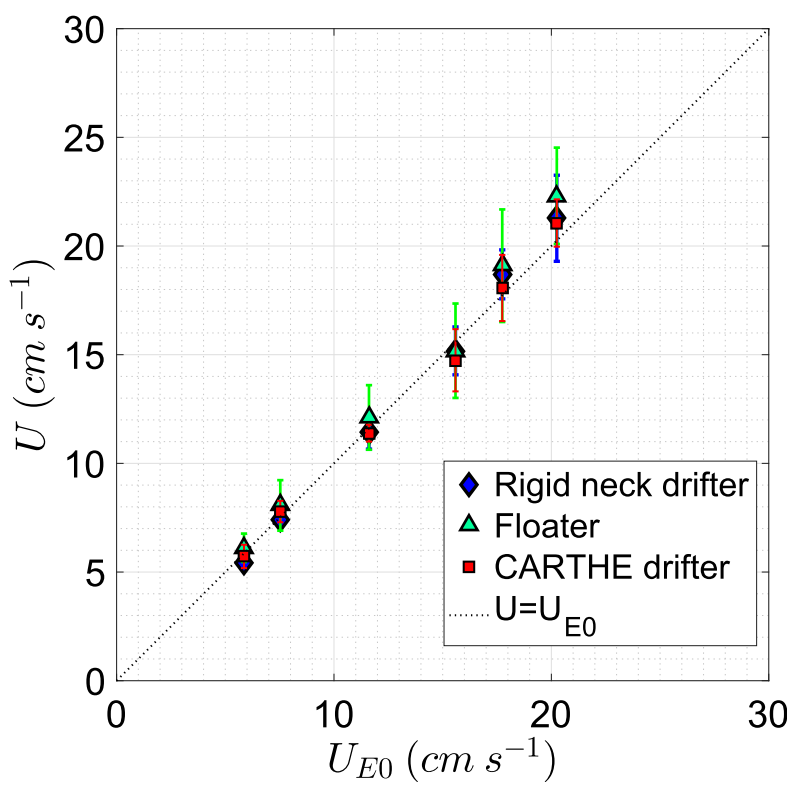

FIG. 9. Experiment 1: Drifters' velocities $U$ as a function of $U_{E 0}$. The error bars represent one standard deviation about the mean.

Compared to the gray solid line, which marks the velocity profile in the absence of wind, the Lagrangian velocity profiles exhibit a very strong gradient of velocity, where the velocity is divided by a factor of 2 across the upper $0.03 \mathrm{~m}$, the draft of the floater. This increase of momentum at the surface is provided mostly by the interaction with the wind across the airsea interface. For the maximum wind speed tested, $U_{10}=23 \mathrm{~m} \mathrm{~s}^{-1}$, the shear velocity reaches considerable values: $\Delta U_{L}=0.4 \mathrm{~m} \mathrm{~s}^{-1}$ across the floater's draft and $\Delta U_{L}=0.6 \mathrm{~m} \mathrm{~s}^{-1}$ across the CARTHE drifter's draft. In that case, the velocity at the bottom of the drogue is less than half the velocity without wind: $U_{L}\left(z_{d}\right)<0.5 U_{E 0}$. These strong shear conditions constitute a great challenge for a drifter to represent accurately its volume of water. Having a small size vertically is an advantage, as it reduces the shear velocity over the drifter's body.

The CARTHE and rigid neck drifters and the floater's velocities are plotted next to the surface dye velocities and the Lagrangian velocities depth integrated over their drifter's respective drogue depth $z_{d}$ and $z_{f}$, in Fig. 13. The surface dye velocity increases steadily with neutral wind speed at a rate $\alpha_{0}=0.024$ such as $U^{\text {Dye }}=\alpha_{0} U_{10}$. The floater velocity increases with neutral wind speed at a rate of $\alpha_{1}=0.023$ for $U_{10} \leq 15 \mathrm{~m} \mathrm{~s}^{-1}$ : $U^{\text {Floater }}=\alpha_{1} U_{10}$, and then at a slower rate of $\alpha_{2}=0.009$ for $U_{10} \geq 15 \mathrm{~m} \mathrm{~s}^{-1}: U^{\text {Floater }}=\alpha_{2} U_{10}$. For $U_{10} \geq 15 \mathrm{~m} \mathrm{~s}^{-1}$, the measured wind waves' significant wave height $H_{s}$ is higher than the floater: $H_{s} \geq 0.03 \mathrm{~m}$. The result is that airflow separation occurs at the wave crest, and a turbulent rough atmospheric boundary layer is created. In this higher wind speed regime, the wind stress on the floater increases slower than at lower wind speeds, when the atmospheric flow is smoother as a result of smaller and less steep waves.

The CARTHE and rigid neck drifters' velocities are virtually equal, increasing slowly with neutral wind speed for $U_{10} \leq 15 \mathrm{~m} \mathrm{~s}^{-1}$ at a rate of $\beta_{1}=0.003$ : $U^{\text {CARTHE }}=\beta_{1} U_{10}$. For $U_{10} \geq 15 \mathrm{~m} \mathrm{~s}^{-1}$ they increase even slower with neutral wind speed, for the same reason of airflow separation at wave crests, at a rate of $\beta_{2}=0.0001: U^{\text {CARTHE }}=\beta_{2} U_{10}$. The drogue was effective at anchoring the drifters in the water. It also indicates that these wind waves did not provoke wave rectification motions in these designs, mainly because their wave lengths $[\lambda=O(0.01) \mathrm{m}]$ were too short with respect to the drifters' size $[O(0.20) \mathrm{m}]$. This is likely to be different in the open ocean, where waves have fetch to develop into longer wavelengths $(>1 \mathrm{~m})$ and where one should expect the rigid neck drifter velocity to increase significantly as was seen in the second experiment.

The comparison of the drifter's velocities and the Lagrangian velocities is given a closer look in Fig. 14. The "absolute" slip velocity is defined as the difference between a drifter's velocity and the Lagrangian velocity depth integrated over its draft:

$$
U_{\text {slip }}^{\text {CARTHE }}=U^{\text {CARTHE }}-\left\langle U_{L}\right\rangle_{\left[0, z_{d}\right]}
$$

and

$$
\left.U_{\text {slip }}^{\text {Floater }}=U^{\text {Floater }}-\left\langle U_{L}\right\rangle_{\left[0, z_{f}\right.}\right]
$$

The absolute slip velocities of the CARTHE drifter and the floater are plotted in Fig. 14 as a function of $U_{10}$. For both drifters, the slip velocities diminish with increasing wind speed: from 14 to $1 \mathrm{~cm} \mathrm{~s}^{-1}$ for the floater, and from 3 to $0.1 \mathrm{~cm} \mathrm{~s}^{-1}$ for the CARTHE drifter, for $U_{10}$ varying between 8.1 and $23 \mathrm{~m} \mathrm{~s}^{-1}$. When wind speed increases above a certain threshold $\left(U_{10}>15 \mathrm{~m} \mathrm{~s}^{-1}\right.$ in our experiment), and wind-waves grow and steepen, then the wind flow separates at the wave crests [e.g., see Buckley and Veron (2016) for visualization of the airflow detachment above wave crests at high wind speeds] and the low-profile floater is positioned in the wake of the waves, in the low pressure zone. Therefore, in between wave crests, the floater spends less time exposed to strong direct wind forcing than it might at lower wind speed and lower wave steepness, allowing the floater (and thus the full drifter as well) to follow the surface current more accurately and to reduce the slip velocity. This transition of airflow regime has been observed and 


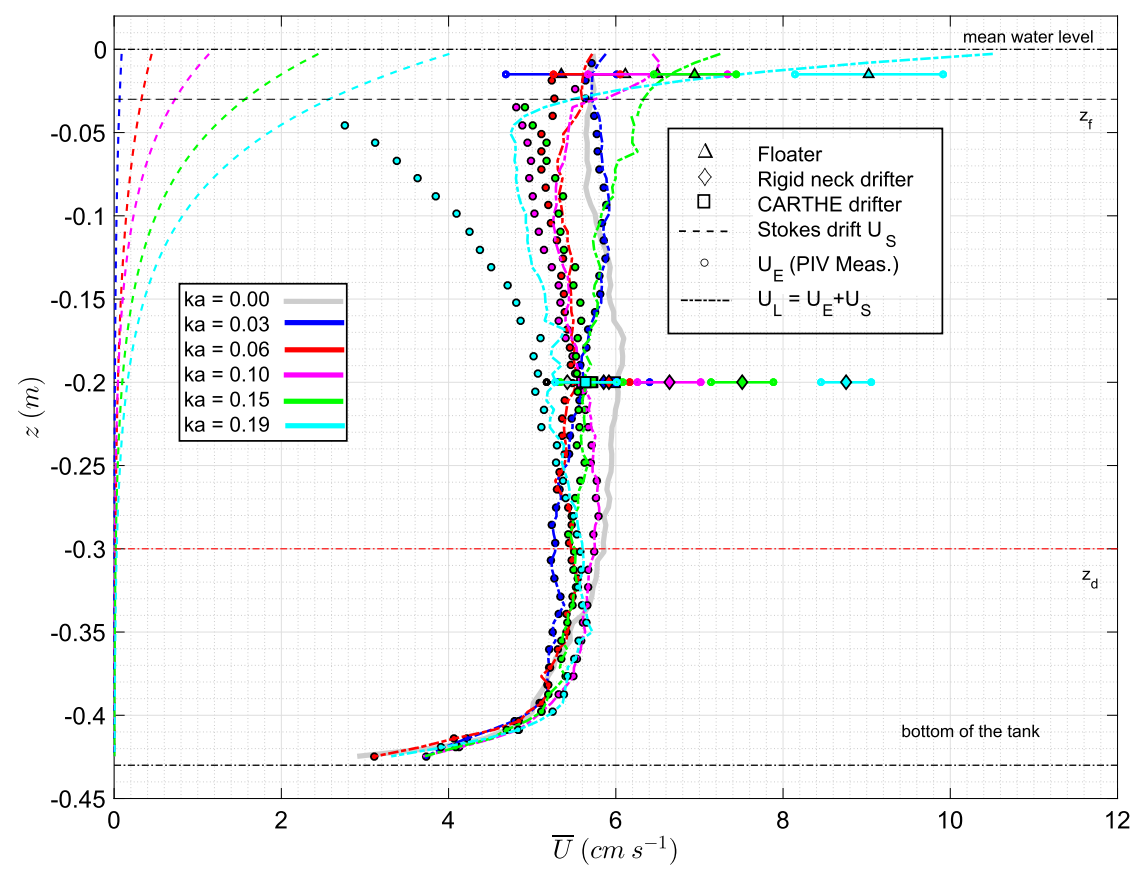

FIG. 10. Experiment 2: Velocities in the tank for different waves, color coded by $k a$. The Stokes drift velocity profiles $U_{S}(z)$ for the monochromatic waves as per Eq. (2) (colored dashed lines). The velocity profiles $U_{E}(z)$ retrieved by PIV for each of the waves (colored circles). The Lagrangian velocity profiles $U_{L}(z)=U_{E}(z)+U_{S}(z)$ (colored dashed-dotted lines). The velocity profile measured by PIV without waves (water pump frequency $f=15 \mathrm{~Hz}$; $U_{E 0}=0.06 \mathrm{~m} \mathrm{~s}^{-1}$; solid gray line). The symbols $(\triangle, \diamond$, and $\square)$ are the drifters' speed (floater, rigid neck, and CARTHE, respectively), and the error bars represent one standard deviation about the mean. The full-length horizontal lines indicate the following: at $z=0 \mathrm{~m}$, the mean water level; at $z_{f}=-0.03 \mathrm{~m}$, the bottom of the floater; at $z_{d}=-0.30 \mathrm{~m}$, the bottom of the drifter drogue; at $z=-0.43 \mathrm{~m}$, the bottom of the tank.

discussed in many studies previously, for example in $\mathrm{Wu}$ (1975) who studied the currents below and the airflow above the air-water interface for various wind conditions, or in Donelan et al. (2004) where the airflow above the water surface at high wind speed has been scrutinized. So the CARTHE drifter has a satisfactory low windage at all wind speeds, while the floater show significant windage for wind speeds less than $U_{10}=15 \mathrm{~m} \mathrm{~s}^{-1}$.

Estimates of $U_{10}$, from atmospheric models and in situ measurements, are reliable and generally available globally and at all times. However, this is not true for ocean currents, which are generally not well known, unless drifters are present at the moment and at the place of interest. This is why the drifter's slip velocity is often expressed as a function of $U_{10}$. Then our measurements translate into

$$
U_{\text {slip }}^{\text {CARTHE }}<0.005 U_{10}
$$

and

$$
U_{\text {slip }}^{\text {Floater }}<0.02 U_{10} .
$$

To the authors' knowledge, it is the first time slip velocity measurements over such a range of wind speeds, and wind-induced shear velocity, have been reported for a surface drifter. For comparison a slip velocity on the order of $0.2 \%$ of $U_{10}$ was reported for the CODE drifter (drogued at $1 \mathrm{~m}$ ), for wind speeds of $U_{10}=10 \mathrm{~m} \mathrm{~s}^{-1}$ or less (Poulain et al. 2002; Poulain 1999; Poulain et al. 2013). For the NOAA SVP drifter (drogued at $15 \mathrm{~m}$ ), a slip velocity of $0.1 \%$ of $U_{10}$ was previously reported by Niiler et al. (1995) for wind speeds of $U_{10}=10 \mathrm{~m} \mathrm{~s}^{-1}$ or less.

The results of these three laboratory experiments, covering a wide range of surface velocity shear, are compelling evidence that the CARTHE drifter and the floater are appropriate instruments capable of measuring the surface transport even in the presence of waves and strong winds. Rigid neck drifters, like vertical rigidbodied cylinders, have been shown to be prone to wave rectification issues and thus should be avoided for the measure of near-surface currents. 


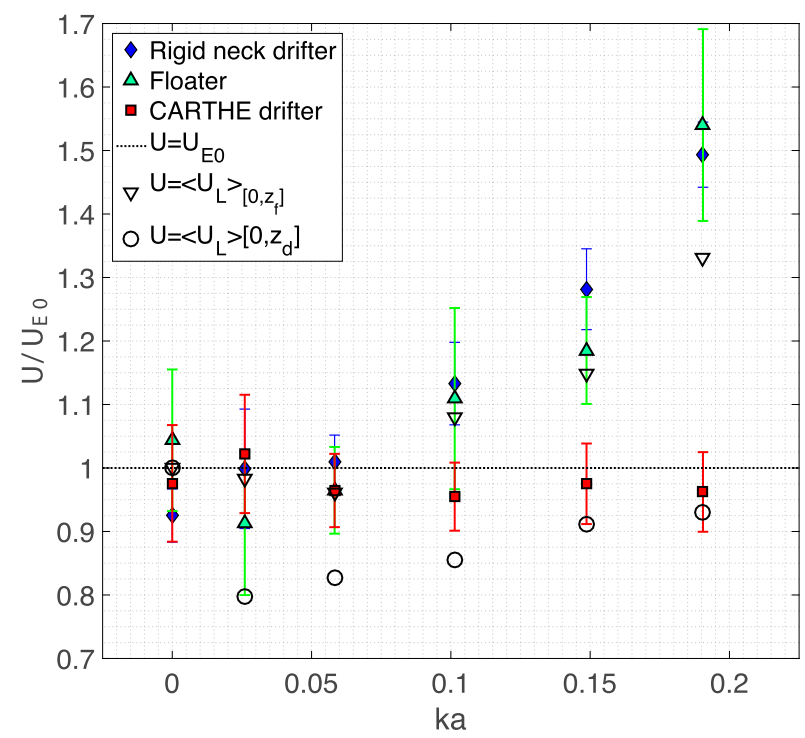

FIG. 11. Experiment 2: Drifters velocities as a function of $k a$, scaled by the mean background flow velocity $U_{E 0}=0.06 \mathrm{~m} \mathrm{~s}^{-1}$. The colored symbols $(\triangle, \diamond$, and $\square)$ are the mean velocities of the drifters (floater, rigid neck, and CARTHE, respectively), and the error bars represent one standard deviation about the mean. Also indicated is $U=U_{E 0}$ (dotted line). The symbol $\nabla$ represents $U=\left\langle U_{L}\right\rangle_{\left[0, z_{f}\right]}$, the near-surface Lagrangian velocity depth averaged over the floater's draft $z_{f}$, and the circles represent $U=\left\langle U_{L}\right\rangle_{\left[0, z_{d}\right]}$, the Lagrangian velocity depth averaged over the CARTHE drifter's draft $z_{d}$.

\section{Field study: Direct comparison with the CODE drifter in coastal environment}

\section{a. Experimental method}

While the laboratory setting helped refine the CARTHE drifter design concept, mainly by making the floater more aerodynamic and by replacing the rigid neck by a flexible tether, these measurements were made in unidirectional flows with half-scale models. It is also necessary to evaluate the full-size drifter in the conditions of a real deployment in the ocean. An ideal instrument to compare the CARTHE drifter to is the CODE drifter (Davis 1985a): First, it targets the average currents over the first meter below the surface, and it has well-known Lagrangian qualities being minimally influenced by wind and waves (Poulain 1999; Poulain et al. 2002). Second, it has been used in many experiments over the past 30 years (Davis 1985b; Ohlmann and Niiler 2001; Ohlmann et al. 2001; Ohlmann and Niiler 2005; Poulain et al. 2013; Poje et al. 2014; Röhrs et al. 2012; Röhrs and Christensen 2015), thus data collected in the future with the CARTHE drifter could be compared directly with previous datasets.

\section{1) DRIFTERS}

A series of drifter deployments were conducted off the coast of Miami, Florida, to compare the trajectories of the CARTHE and CODE drifters when released next to each other in the ocean. A rigid neck drifter and an iSphere drifter (manufactured by MetOcean), most known as an oil spill-following drifter (Reed et al. 1994), were included in the experiment to illustrate how wind and wave conditions may lead different surface drifter designs to separate.

Figure 15 is a picture of a typical release. The four drifters were launched simultaneously, along a line across the wind, with a maximum separation of about $5 \mathrm{~m}$ between the first and the last drifter. This grouped configuration was chosen to ensure all drifters started in the same body of water but at the same time did not interfere with each other's wake, or get entangled together.

The CARTHE drifter used is the full-scale instrument with a drogue's draft reaching $0.60-\mathrm{m}$ depth. The float carried a set of batteries and a small GPS unit (LOCOSYS GT-31) to log its position at $1 \mathrm{~Hz}$ with $3-\mathrm{m}$ spatial accuracy; the GPS unit was used in previous coastal drifter experiments to resolve wave motions and surfzone circulation (Pearman et al. 2014; MacMahan et al. 2009). The same type of GPS is used in the four drifters. The CODE drifter's drogue is made of four vinyl vanes $0.5 \mathrm{~m}$ wide, $0.9 \mathrm{~m}$ tall, centered at $0.5 \mathrm{~m}$ deep, mounted across a vertical 1.25-m-tall hollow PVC pipe holding the GPS logger inside an enclosure protruding through the surface. Four small yellow PVC floats are attached to the upper extremities of the vanes by flexible lines. The rigid neck drifter has the same dimensions and shape as the CARTHE drifter, but its drogue is made of two interlocked plywood sheets and the float is an aluminum hollow ring. The GPS was in a waterproof box located at the center of the ring tied to the top of the rigid neck at the center of the ring. The iSphere is a 0.40-m-diameter sphere that is half submerged. The same GPS was installed on top of the emerged half. Its drift is known to be driven as much by wind and waves as by surface currents. Its trajectories tend to separate quickly from the CODE drifters, as seen in recent experiments on surface transport in the North Sea (Röhrs et al. 2012; Röhrs and Christensen 2015; Jones et al. 2016).

\section{2) DEPLOYMENT CONDITIONS}

The experiment was run in a location with a bottom varying gently between 15 - and $20-\mathrm{m}$ depth. The shallow and mostly flat bathymetry reduces the chances of releasing the drifters into different coherent structures, or 


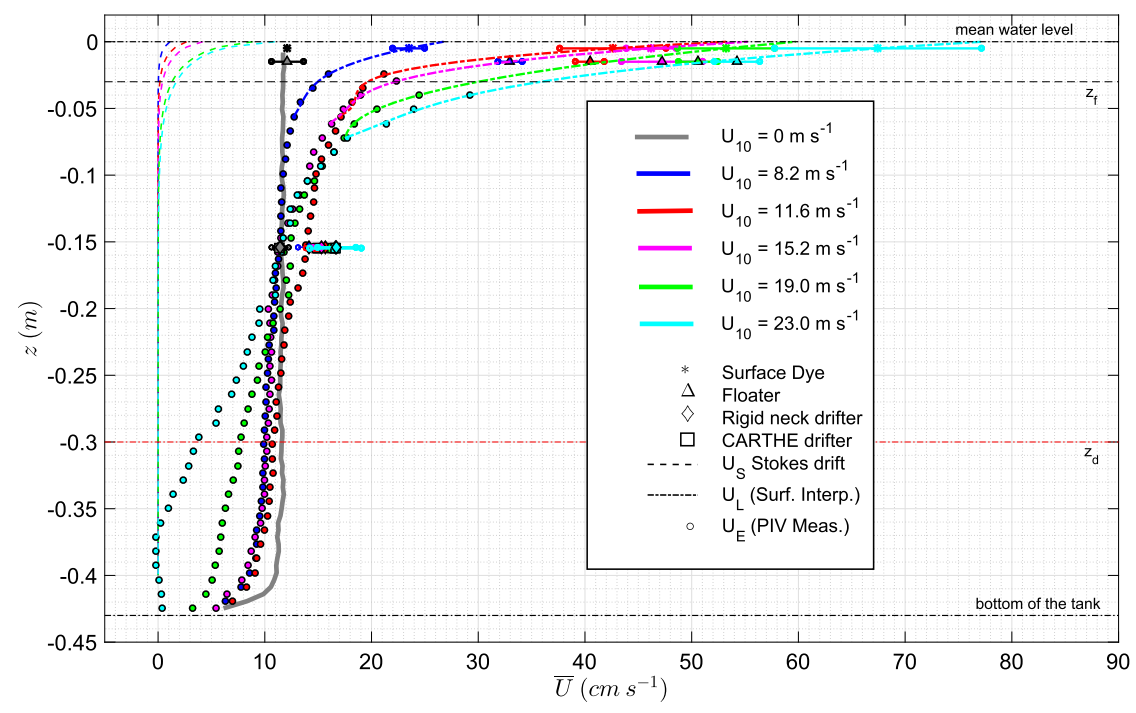

FIG. 12. Experiment 3: Velocities in the tank for different wind speeds, color coded by $U_{10}$. The Stokes drift velocity profiles $U_{S}(z)$ for the measured wave spectra as per Eq. (3) (colored dashed lines). The colored circles are the velocity profiles $\left[U_{E}(z)\right]$ retrieved by PIV for each wind. The solid gray line is the velocity measured by PIV without wind (water pump frequency $f=30 \mathrm{~Hz} ; U_{E 0}=0.12 \mathrm{~m} \mathrm{~s}^{-1}$; solid gray line). The asterisk, located at $z=-0.005 \mathrm{~m}$ (average depth of the surface dye), represents the mean speed of the surface dye. The nearsurface Lagrangian velocity profiles $\left(U_{L}^{\text {Surf.Interp. }}\right)$, interpolated between the uppermost part of the PIV profiles and the surface dye speed are denoted by dashed-dotted lines. The symbols $(\triangle, \diamond$, and $\square$ ) are the drifters speed (floater, rigid neck, and CARTHE, respectively), and error bars representing one standard deviation about the mean. The other horizontal lines indicate the following: at $z=0 \mathrm{~m}$, the mean water level; at $z_{f}=-0.03 \mathrm{~m}$, the bottom of the floater; at $z_{d}=-0.30 \mathrm{~m}$, the bottom of the drifter drogue; and at $z=-0.43 \mathrm{~m}$, the bottom of the tank.

different channels, which could entrain the drifters in different directions.

The deployments started on a flooding tide, continued over slack tide, and ended by the end of the ebb tide, thus covering a range of direction and intensities of the tidal currents.

In light of the laboratory experiments, ocean conditions involving vertical surface velocity shear were sought after in order to enhance the possible differences between drifters' trajectories. Therefore, the field comparison was carried out on a day of sustained southerly winds (blowing toward the north), with gusts as high as $10 \mathrm{~m} \mathrm{~s}^{-1}$, which was the upper limit for safe small-boat operations. Wind speed and direction were collected at the Virginia Key NOAA station located $2 \mathrm{mi}$ from the experiment every $6 \mathrm{~min}$, as well as on the small boat, with a handheld anemometer every $15 \mathrm{~min}$. Both measurements agreed well and the NOAA measurements are used in the results presented below.

The observed wind waves reached a maximum significant wave height of $1 \mathrm{~m}$, with occasional whitecaps from breaking waves. Floating seagrass and sargassum weeds were observed to gather into windrows at moments, signaling the presence of Langmuir circulations, as a result of the interaction of surface Stokes drift and vertical shear (Langmuir 1938; Thorpe 2004).

Handheld CTD casts were performed every $30 \mathrm{~min}$, showing a well-mixed surface layer, 6-8 $\mathrm{m}$ thick, with weak stratification below that depth during the whole length of the experiment.

The drifters were deployed for 10-20 min, being collected as soon as they separated approximately $200 \mathrm{~m}$, to ensure that they were always drifting in a current of similar dynamical characteristics and that their different behavior would be due to only their design. This process was repeated six times.

Surface flow dynamics in the field were certainly more complex than the ones in the laboratory setting: they changed over time in the atmosphere and the ocean, at a different rate, and in different directions.

\section{b. Field results}

\section{1) Trajectories And average Velocities}

Table 4 compiles all drifters' average velocities and direction for each deployment, as well as the wind speed $U_{10}$, 


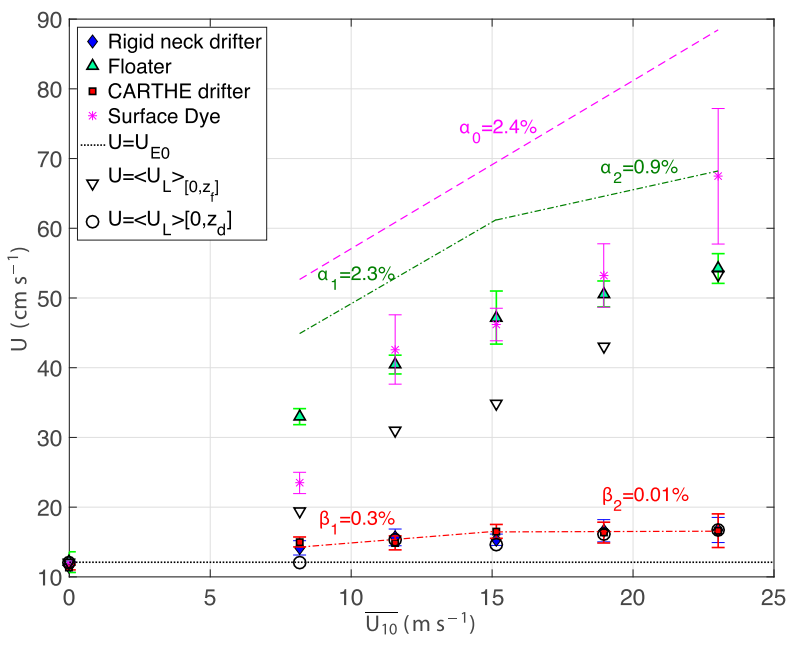

FIG. 13. Experiment 3: Drifter's velocities as a function of $U_{10}$; $U_{E 0}=0.12 \mathrm{~m} \mathrm{~s}^{-1}$ is the mean background flow over the drifter draft in the absence of wind. The symbol $\nabla$ represents the near-surface Lagrangian velocity depth averaged over the floater depth $z_{f}=-0.03 \mathrm{~m}:\left\langle U_{L}\right\rangle_{\left[0, z_{f}\right]}=\int_{0}^{z_{f}} U_{L}^{\text {Surf.Interp. }}(z) /\left|z_{f}\right| d z$. The circle represents the Lagrangian velocity integrated over the draft of the full drifter $z_{d}=-0.30 \mathrm{~m}: \quad\left\langle U_{L}\right\rangle_{\left[0, z_{d}\right]}=\left[\int_{0}^{z_{f}} U_{L}^{\text {Surf.Interp. }}(z) d z+\int_{z_{f}}^{z_{d}} U_{E}(z)\right] /\left|z_{d}\right| d z$. The slope $\alpha_{0}=2.4 \%$ of dye velocity as function of wind speed (magenta dashed line). The slopes $\alpha_{1}=2.3 \%$ and $\alpha_{2}=0.9 \%$, of the floater velocity as function of wind speed, with the change happening at $U_{10}=15 \mathrm{~m} \mathrm{~s}^{-1}$ (blue dashed-dotted lines). The slopes $\beta_{1}=0.3 \%$ and $\beta_{2}=0.01 \%$, of the CARTHE drifter velocity as function of wind speed, with the change happening at $U_{10}=15 \mathrm{~m} \mathrm{~s}^{-1}$ (red dashed-dotted lines). Error bars represent one standard deviation about the mean.

wind direction, and gust speed. The direction in which the wind was blowing is given for a direct comparison with the direction of the averaged drifters' velocities. The CODE drifter velocity is used as the reference for the near-surface current resulting from the contributions of the tidal flow, the wind-induced current, and the wave-induced Stokes drift. There is no significant difference between the CODE and the CARTHE drifters' observed average velocities in all deployments, as the currents shifted from north to east. Both drifters traveled in the same direction in each deployment, ranging from $30^{\circ}$ to the left of the wind to $40^{\circ}$ to the right of the wind. The iSphere, the drifter without an underwater drogue, is clearly more influenced by the wind and surface waves (including surface Stokes drift and wave rectification), as proved by its higher velocities and its direction closer to the wind direction. The rigid neck and the CARTHE drifters have the same shape and size, except for the link between the floater and the drogue, but their velocities are significantly different in all six trials: the rigid neck drifter moved $30 \%$ faster than the CARTHE drifter, and even went in a different direction in the last two trials, in between the iSphere and the CODE drifters' direction. As predicted in the

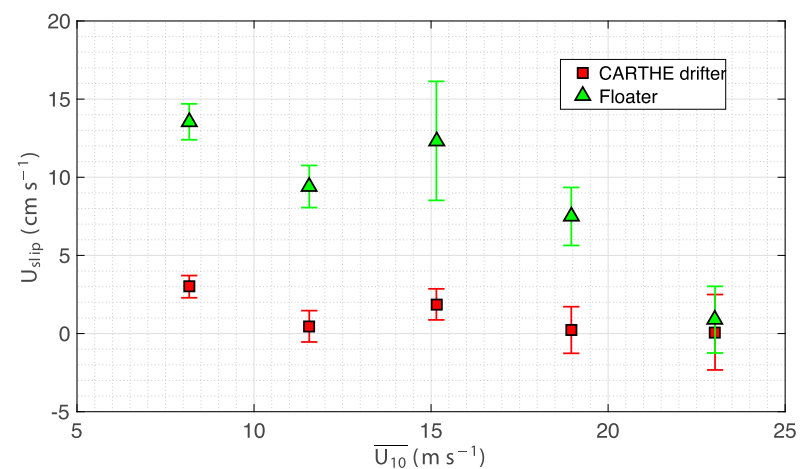

FIG. 14. Experiment 3: Slip velocities as a function of $U_{10}$ : $U_{\text {slip }}^{\text {CARTHE }}=U^{\text {CARTHE }}-\left\langle U_{L}\right\rangle_{\left[0, z_{d}\right]}$ and $U_{\text {slip }}^{\text {Floater }}=U^{\text {Floater }}-\left\langle U_{L}\right\rangle_{\left[0, z_{f}\right]}$, of the CARTHE drifter and the floater, respectively. Error bars represent one standard deviation about the mean.

laboratory experiment, the wind waves certainly induced a rectifying motion on the rigid neck drifter, making it travel faster than the flow in the direction of the waves.

As visual examples, $16 \mathrm{~min}$ of trajectories of the fourth and sixth deployments are plotted in Figs. 16a-d. In the fourth deployment (Figs. 16a,b), all the drifters traveled mostly in the same direction toward the north. The iSphere, with an average velocity of $0.32 \mathrm{~m} \mathrm{~s}^{-1}$, moved 5 times faster than the CARTHE and CODE drifters, showing an equal average velocity of $0.06 \mathrm{~m} \mathrm{~s}^{-1}$. A closeup on the trajectories of the CARTHE and CODE drifters is shown in Fig. 16b, where their individual parallel paths are more clearly defined. The rigid neck drifter path shows the same patterns as the CARTHE drifter path, but every segment is slightly elongated, as it moved on average $30 \%$ faster at $0.08 \mathrm{~m} \mathrm{~s}^{-1}$. This is the result of the wave rectification motions acting on the rigid neck design. In the sixth deployment (Figs. 16c,d), the drifters take different paths: The iSphere moved at $0.32 \mathrm{~m} \mathrm{~s}^{-1}$ at $50^{\circ}$ to the left of the wind entrained by wind drag, surface Stokes drift, and rectification motions. The rigid neck drifter moved at $0.02 \mathrm{~m} \mathrm{~s}^{-1}$ at $30^{\circ}$ to the left of the wind, unaffected by windage issues but severely rectifying the short wind waves. The CODE drifter and the CARTHE drifter took parallel paths at $40^{\circ}$ to the right of the wind, or $90^{\circ}$ to the right of the iSphere trajectory, at about $0.02 \mathrm{~m} \mathrm{~s}^{-1}$. This shows clearly that both the CODE and CARTHE drifters have a low wind drag and that their trajectories were not affected by rectification motions caused by the wind waves.

\section{2) Separation Statistics}

To quantify the differences between the drifters' trajectories, we calculated separation statistics over the six deployments. 

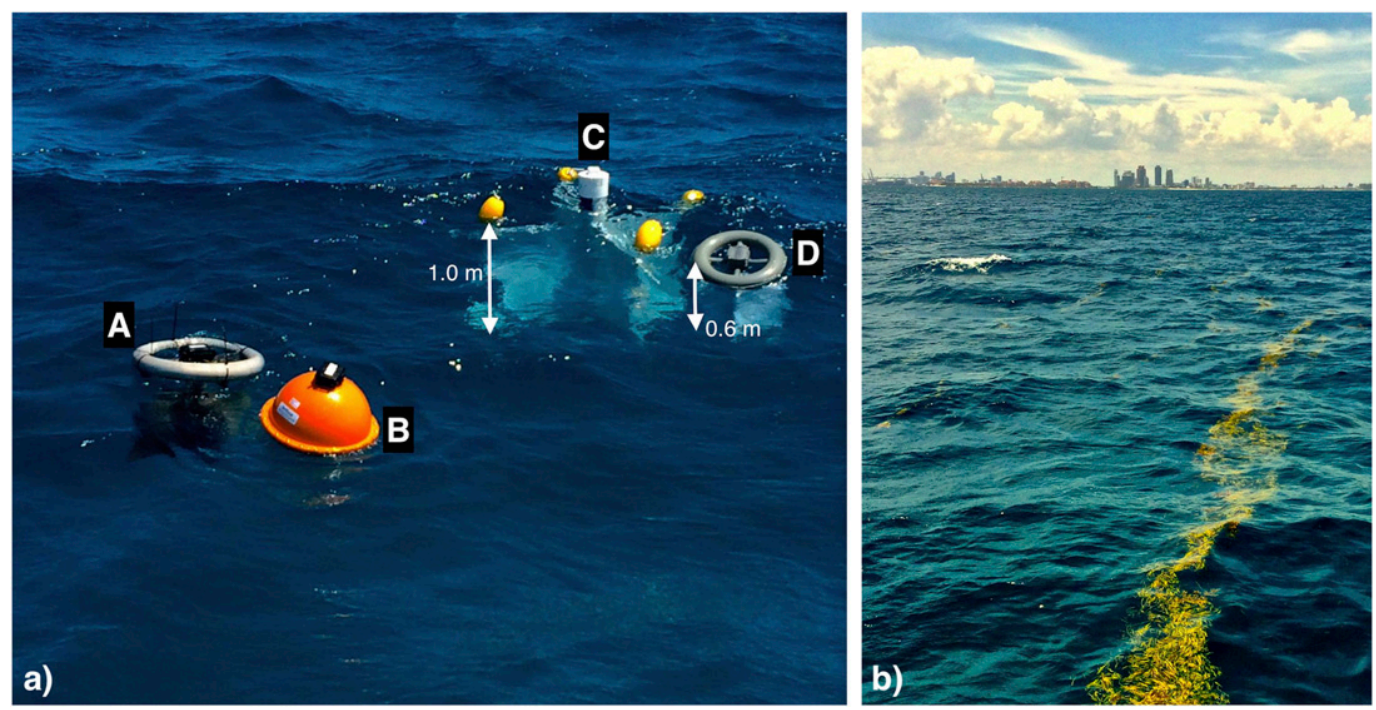

FIG. 15. Field experiment: (a) Drifters deployed during the field drift comparison tests: (left)-(right) A, the rigid neck drifter with its silver torus float at the surface and a dark drogue underwater; B, the orange iSphere holding an extra GPS in a black box on top of the sphere; C, the CODE drifter with its four yellow buoys and white GPS housing visible at the surface, and its 1-m-deep underwater white drogue; D, the CARTHE drifter with its gray torus float at the surface and its 0.6-m-deep underwater white drogue. (b) Picture of the sea surface looking downwind showing the accumulation of floating algae along windrows and occasional wave breaking.

Figure 17a shows, for each drifter, the distance from launch position as a function of time, averaged over all six trials, for the first $10 \mathrm{~min}$ (length of the shortest trial). The error bars represent one standard deviation about the mean. The iSphere and the rigid neck drifters move faster than the CARTHE and the CODE drifters, as they respond to the additional forcings from the wind and the wind waves. The CARTHE and the CODE drifters' curves are virtually identical: on average, the total distance the CARTHE and CODE drifters have traveled differs by only $1.5 \mathrm{~m}$ after $10 \mathrm{~min}$. In other words, their speed difference is about $0.25 \mathrm{~cm} \mathrm{~s}^{-1}$, an order of magnitude less than the accuracy of the current velocity measurements obtained from the CODE trajectories (Poulain 1999; Poulain et al. 2002).

The root-mean-square [RMS $(t)]$ of the relative separation $D(t)$ between each drifter and the CODE drifter is plotted in Fig. 17b, normalized by the total distance traveled by the CODE drifter $C(t=600 \mathrm{~s}) \|$ for each deployment $i$ and averaged over all six trials, for the first $10 \mathrm{~min}$, according to the following equation:

$$
\operatorname{RMS}(t)=\sqrt{\frac{1}{6} \sum_{i=1}^{6} \frac{D_{i}^{2}(t)}{C_{i}^{2}(t=600 s)}} .
$$

The error bars represent one standard deviation about the mean. The vertical axis is on a logarithmic scale to help visualize small variations in the temporal evolution of the separation of each drifter. The iSphere and the rigid neck drifter separations with respect to the CODE drifter clearly keep increasing with time over the first $10 \mathrm{~min}$, while the normalized distance between the CARTHE drifter and the CODE drifter barely increased between $t=0 \mathrm{~s}$ and $t=600 \mathrm{~s}$ from 0.191 to 0.204 ,

TABLE 4. Average velocities during the field deployments.

\begin{tabular}{|c|c|c|c|c|c|c|c|c|c|c|c|c|}
\hline \multirow[b]{2}{*}{$\begin{array}{l}\text { Trial } \\
\text { No. }\end{array}$} & \multirow[b]{2}{*}{$\begin{array}{l}\text { Time } \\
(\min )\end{array}$} & \multicolumn{3}{|c|}{ Wind } & \multicolumn{2}{|c|}{ iSphere } & \multicolumn{2}{|c|}{ Rigid neck } & \multicolumn{2}{|c|}{ CODE } & \multicolumn{2}{|c|}{ CARTHE } \\
\hline & & $\begin{array}{c}\overline{U_{10}} \\
\left(\mathrm{~m} \mathrm{~s}^{-1}\right)\end{array}$ & $\begin{array}{c}\text { Direction } \\
\left({ }^{\circ}\right)\end{array}$ & $\begin{array}{c}\text { Gust } \\
\left(\mathrm{m} \mathrm{s}^{-1}\right)\end{array}$ & $\begin{array}{c}\bar{U} \\
\left(\mathrm{~cm} \mathrm{~s}^{-1}\right)\end{array}$ & $\begin{array}{l}\text { Direction } \\
\left(^{\circ}\right)\end{array}$ & $\begin{array}{c}\bar{U} \\
\left(\mathrm{~cm} \mathrm{~s}^{-1}\right)\end{array}$ & $\begin{array}{c}\text { Direction } \\
\left({ }^{\circ}\right)\end{array}$ & $\begin{array}{c}\bar{U} \\
\left(\mathrm{~cm} \mathrm{~s}^{-1}\right)\end{array}$ & $\begin{array}{l}\text { Direction } \\
\left({ }^{\circ}\right)\end{array}$ & $\begin{array}{c}\bar{U} \\
\left(\mathrm{~cm} \mathrm{~s}^{-1}\right)\end{array}$ & $\begin{array}{c}\text { Direction } \\
\left({ }^{\circ}\right)\end{array}$ \\
\hline 1 & 13 & 5.7 & 344.0 & 7.4 & 35.5 & 342.5 & 14.2 & 332.8 & 11.3 & 331.8 & 11.5 & 338.0 \\
\hline 2 & 14 & 6.1 & 352.0 & 7.4 & 36.7 & 345.9 & 14.3 & 339.9 & 11.3 & 337.2 & 11.0 & 334.2 \\
\hline 3 & 17 & 6.7 & 8.0 & 8.5 & 32.6 & 357.6 & 8.5 & 346.3 & 5.1 & 342.5 & 5.2 & 346.4 \\
\hline 4 & 17 & 7.0 & 20.0 & 8.6 & 31.5 & 358.8 & 8.2 & 351.0 & 5.8 & 348.5 & 6.0 & 348.5 \\
\hline 5 & 10 & 5.1 & 22 & 7.2 & 27.1 & 2.9 & 7.7 & 0.8 & 4.5 & 18.1 & 4.3 & 359.3 \\
\hline 6 & 16 & 5.4 & 61 & 6.2 & 22.3 & 8.8 & 2 & 34.3 & 1.6 & 100.6 & 2.9 & 99.1 \\
\hline
\end{tabular}




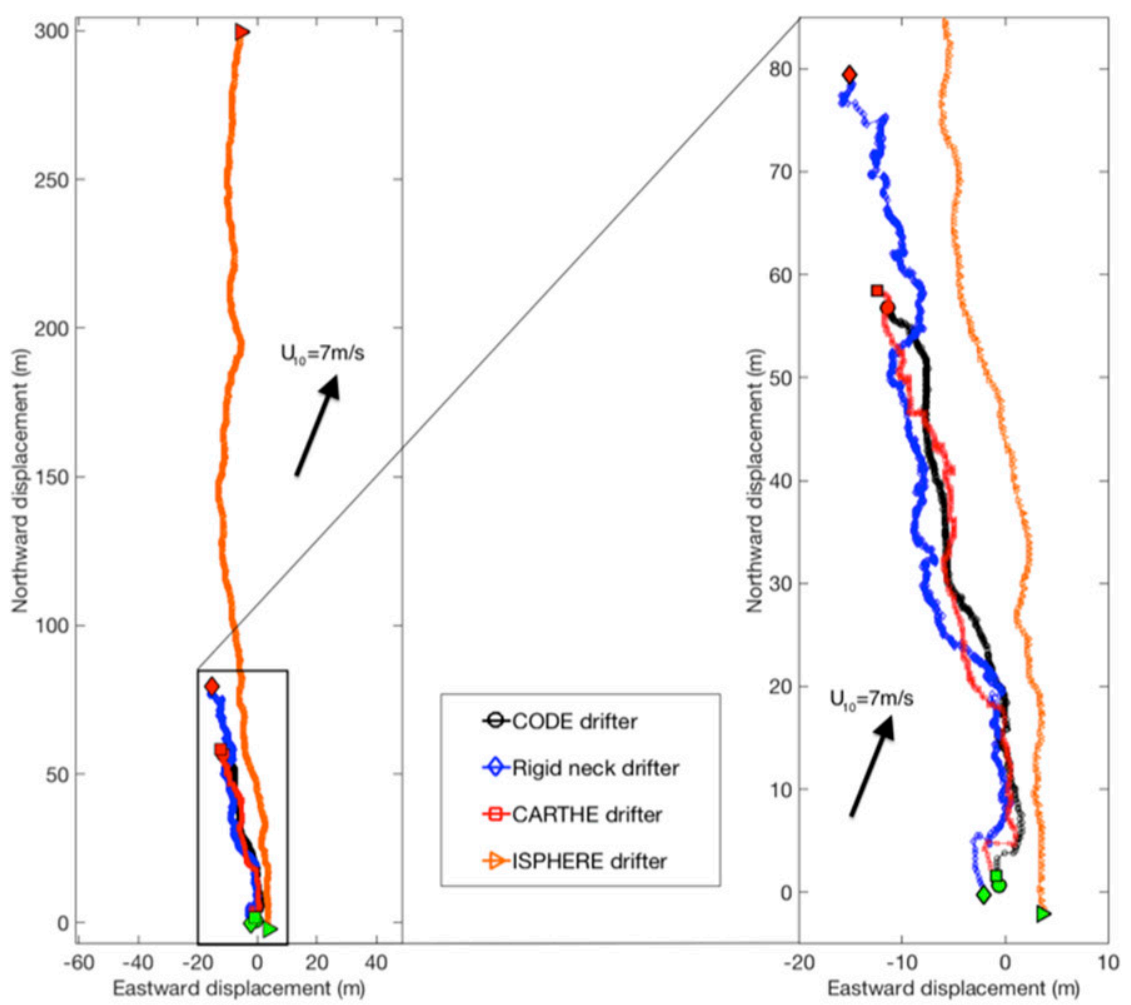

(a)

(b)

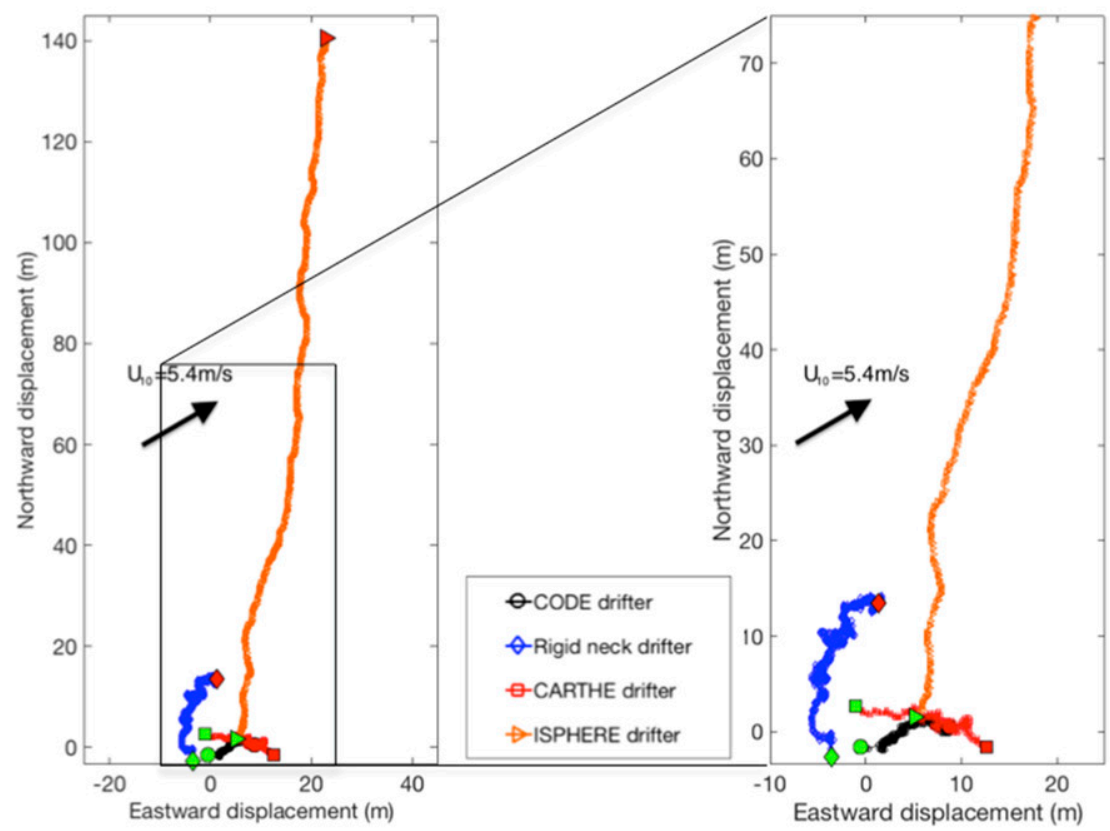

(c)

(d)

FIG. 16. Trajectories of the four drifters over 16 min during the (a),(b) fourth and (c),(d) sixth deployments, and (b),(d) close-up on the CODE, CARTHE, and rigid neck drifters trajectories for the sake of visibility. The launch positions (blue) and the last position of the trajectories (red). The average wind direction in each of the deployments (black arrows). 

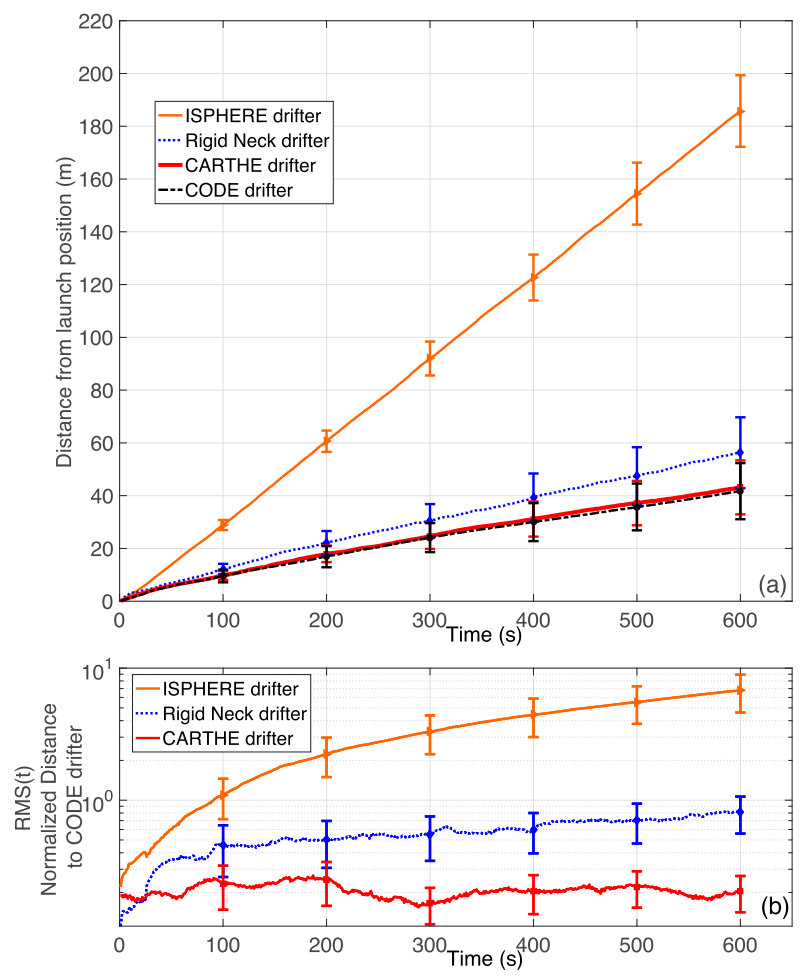

FIG. 17. (a) Distance from launch position of each drifter as a function of time, averaged over all six deployments. (b) RMS of the distance between each drifter and the CODE drifter normalized by the total distance traveled by the CODE drifter for each deployment, and averaged over all six deployments. The error bars represent one standard deviation about the mean.

corresponding on average to an initial separation of $5 \mathrm{~m}$ and a final separation of $6 \mathrm{~m}$ over $10 \mathrm{~min}$, showing that both drifters traveled in the same direction and at the same speed.

Within the variability of the conditions of this experiment, under relatively strong wind and waves forcing, no significant difference was found between the drifting characteristics of the CODE and the CARTHE drifters, while the iSphere and the rigid neck drifters were found to be significantly more sensitive to wind and wind waves, respectively.

\section{Field study: Direct comparison with the CODE drifter in deep ocean environment}

\section{a. Experimental method}

In this instance, the trajectories of four groups of three drifters (CODE, CARTHE, CARTHE floater, rigid neck) are compared in the Florida Current, a strong, deep current. The middle of the Florida Current offers conditions devoid of eddies or other coherent structures, with a predictable and consistent northward flow

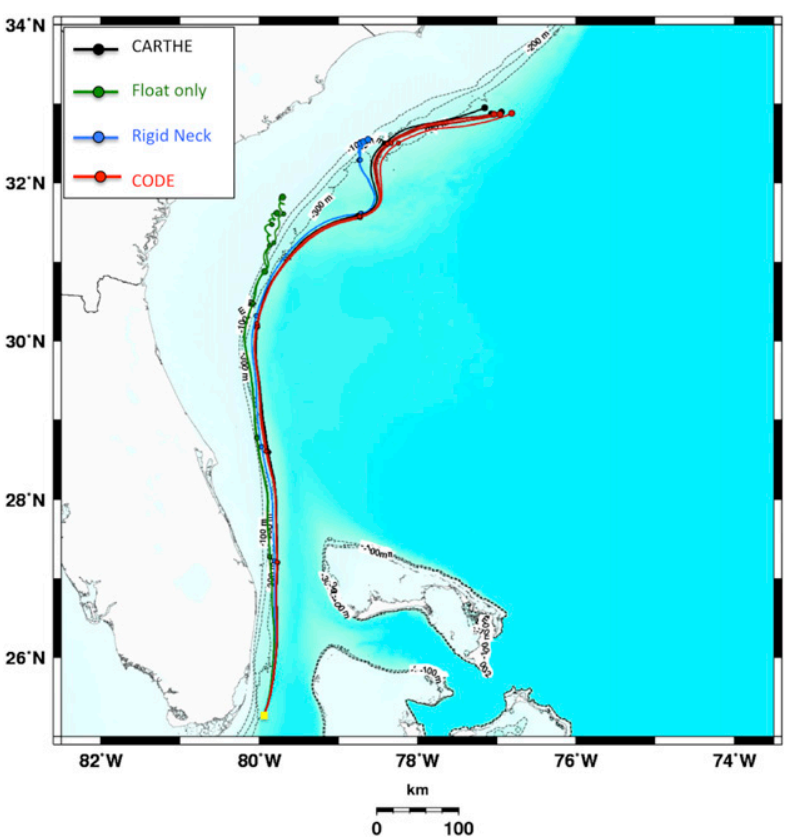

FIG. 18. Deep ocean field experiment: Six-day-long trajectories of the CODE (red), CARTHE (black), rigid neck (blue), and CARTHE floater (blue). The drifters were released offshore from Miami, FL (yellow square). Small dots are marked every $24 \mathrm{~h}$, and large dots are the last known positions. The 100-, 200-, and 300-m isobaths are shown (dashed lines).

at around $2 \mathrm{~m} \mathrm{~s}^{-1}$ still subject to wind and waves generally coming from the east. As such, it is an ideal test bed to show the different motions of different drifters in the actual ocean over extended periods.

The 12 drifters were released simultaneously at the same location (about $25.2522^{\circ} \mathrm{N}, 79.9532^{\circ} \mathrm{W}, 660-\mathrm{m}$ depth) in the Florida Current, flowing north at $2 \mathrm{~m} \mathrm{~s}^{-1}$, under $8-12 \mathrm{~m} \mathrm{~s}^{-1}$ winds coming from the southeast. Their positions were reported every $5 \mathrm{~min}$.

\section{b. Results}

The drifters were taken north by the Florida Current as shown in Fig. 18. However, because of windage and wind-wave rectification motions induced by the wind blowing from the east-southeast, the floater and the rigid neck drifters quickly drifted westward off the path taken by the CODE and the CARTHE drifters. After 3 days, when the wind receded, the floaters were already off the main current, over the continental shelf, where they slowed down considerably. The rigid neck drifters had moved toward the western edge of the Florida Current and were then slower than the CODE and CARTHE drifters.

Under the strong current $\left(U \approx 2 \mathrm{~m} \mathrm{~s}^{-1}\right.$ ), strong winds $\left(U_{10} \approx 10 \mathrm{~m} \mathrm{~s}^{-1}\right)$, and deep ocean wave conditions of this experiment, the CARTHE and CODE drifters 

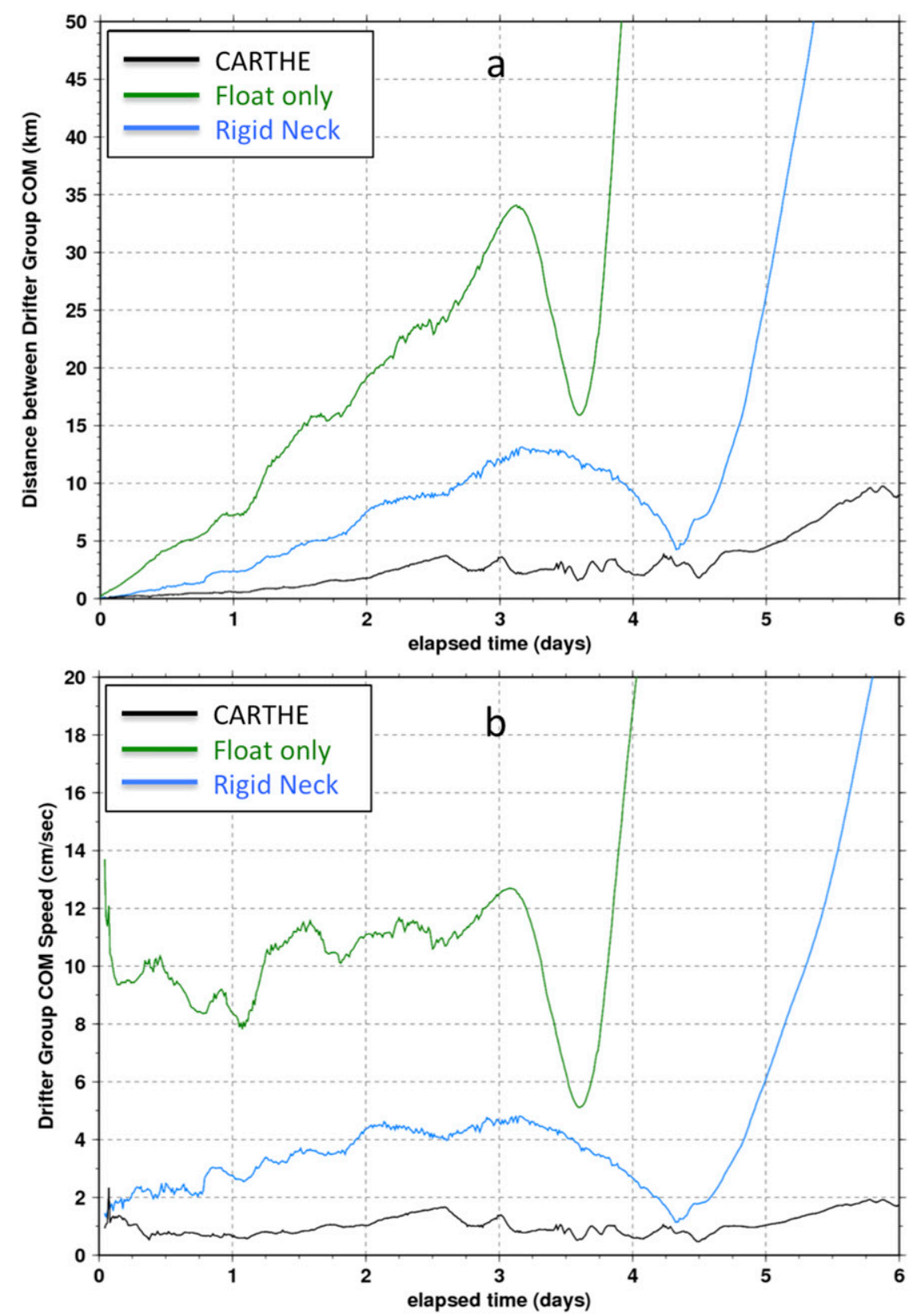

FIG. 19. Deep ocean field experiment: (a) Time series of the deviation distance $(\mathrm{km})$ between each drifter group center of mass with respect to the center of mass of CODE drifters. (b) Time series of the separation rate $\left(\mathrm{cm} \mathrm{s}^{-1}\right)$ of each drifter group center of mass from the center of mass of the CODE drifters.

remained within $5 \mathrm{~km}$ of each other, for over 5 days, as shown in Fig. 19a. The average separation speed between the CODE drifter cluster and each of the other types of drifters, defined as the deviation distance from the CODE center of mass divided by the elapsed time since the drifters were released, is shown in Fig. 19b. The separation rate of the CARTHE drifters remained around $1 \mathrm{~cm} \mathrm{~s}^{-1}$ for 5 days, as long as the drifters were within $5 \mathrm{~km}$ from the CODE center of mass. Thus, the relative difference in speed of the CARTHE drifters with respect to the CODE drifters was about $0.5 \%$. This is especially remarkable in the first 3 days, when the wind was blowing strongly, which led the floaters and rigid neck drifter to separate very quickly from the CODE drifters group, at around 10 and $3 \mathrm{~cm} \mathrm{~s}^{-1}$, respectively, in agreement with the 

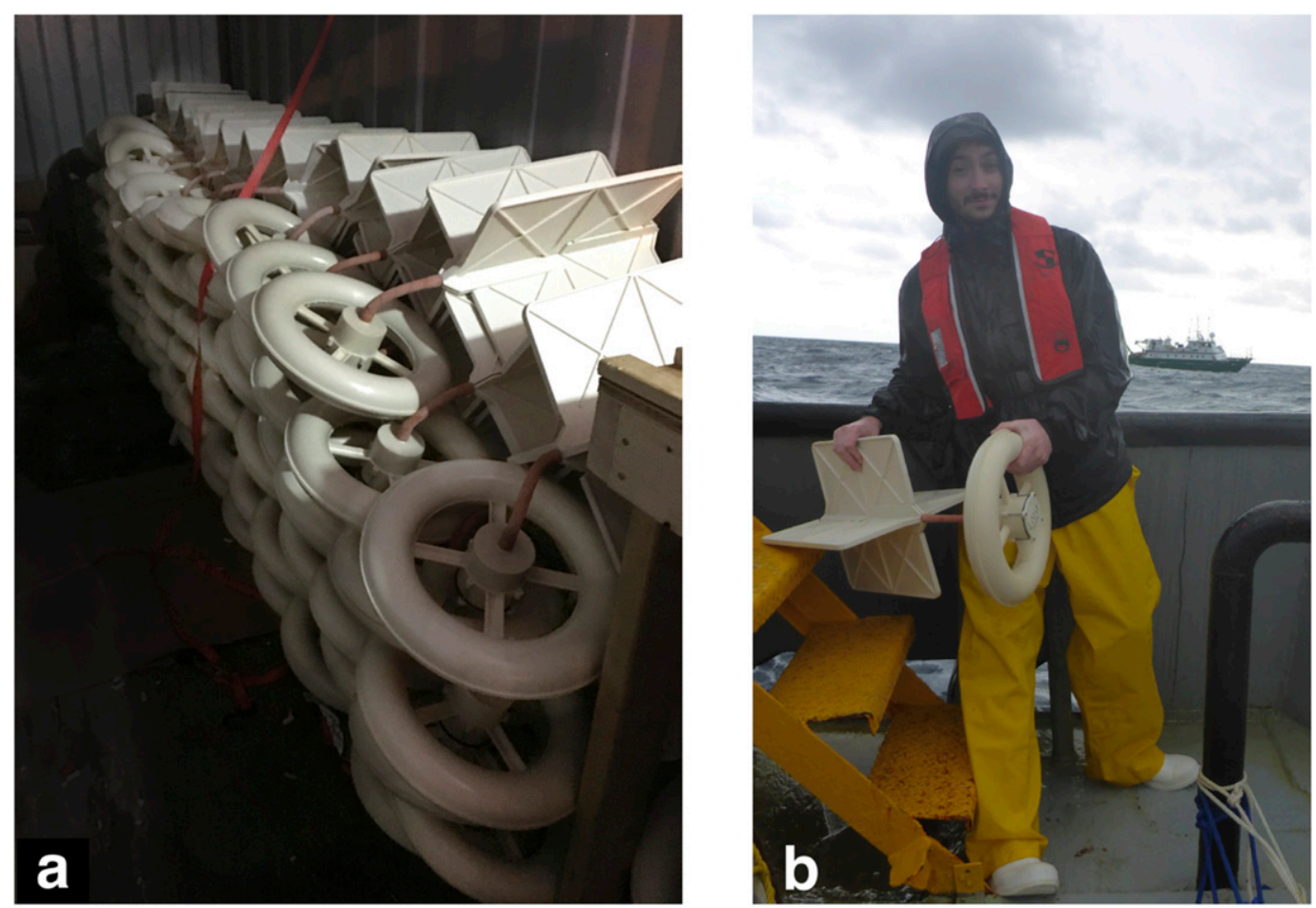

FIG. 20. LASER experiment: (a) 70 CARTHE drifters fully assembled occupy about $5 \mathrm{~m} \times 1 \mathrm{~m} \times 1 \mathrm{~m}$ along the wall of a container. (b) A graduate student waiting for the signal to launch a drifter off the boat in coordination with the other ship, R/V F. G. Walton Smith, in the background.

behavior observed previously in the laboratory and coastal experiments.

\section{Application: Massive-scale sampling in the Gulf of Mexico}

LASER took place in the northern Gulf of Mexico in January-February 2016. The overarching goal was to target submesoscale features and to measure dispersion under harsh winter conditions, in relation to the transport of surface oil spills. Here we focus on the logistics of the drifter deployments and the performance of the drifters during and after LASER as they kept sampling the ocean. The analysis of the drifters' trajectories will be the subject of other papers in the near future.

More than 1000 CARTHE drifters were deployed from two vessels in about 2 weeks at sea. One vessel had a smaller capacity, being able to carry about 200 drifters at a time (in addition to numerous other oceanographic instruments), while the second vessel was devoted to carrying the remaining 900 drifters, including spare parts. The CARTHE drifters' parts were stored in two 20 -ft containers to facilitate transport and storage across land and sea. Once its drifters were released, the smaller-capacity vessel would be refilled with 200 more drifters during port calls. Figure 20a shows 70 CARTHE drifters stacked along a container wall, occupying an area of only $5 \mathrm{~m} \times 1 \mathrm{~m}$ per $1 \mathrm{~m}$ vertically. The drifter design, and its small form factor, was found safe and practical to handle, which was critical at the moment to prepare hundreds of drifters in a limited space, within hours, as soon as a short-lived submesoscale feature of interest was detected. Figure 20b shows a graduate student about to deploy a drifter in one of the multiscale arrays.

Having such a large number of drifters available at all times allowed us to release them for three distinct purposes. First, to obtain real-time maps of the surrounding circulation, a coarse grid of drifters, released along the ships tracks, rapidly and precisely located the mesoscale features. This large view of the surface dynamics was necessary to determine where submesoscale eddies would be more likely to be found or not. Second, once a number of drifters would signal an interesting frontal area, by converging and being trapped in a convergence line, we would reseed more drifters across and around that front to monitor the dynamical evolution of this structure while surveying it with other instruments. Third, we could measure the surface velocity field at high resolution ( $100 \mathrm{~m}, 5 \mathrm{~min}$ ) over a large area (initially 


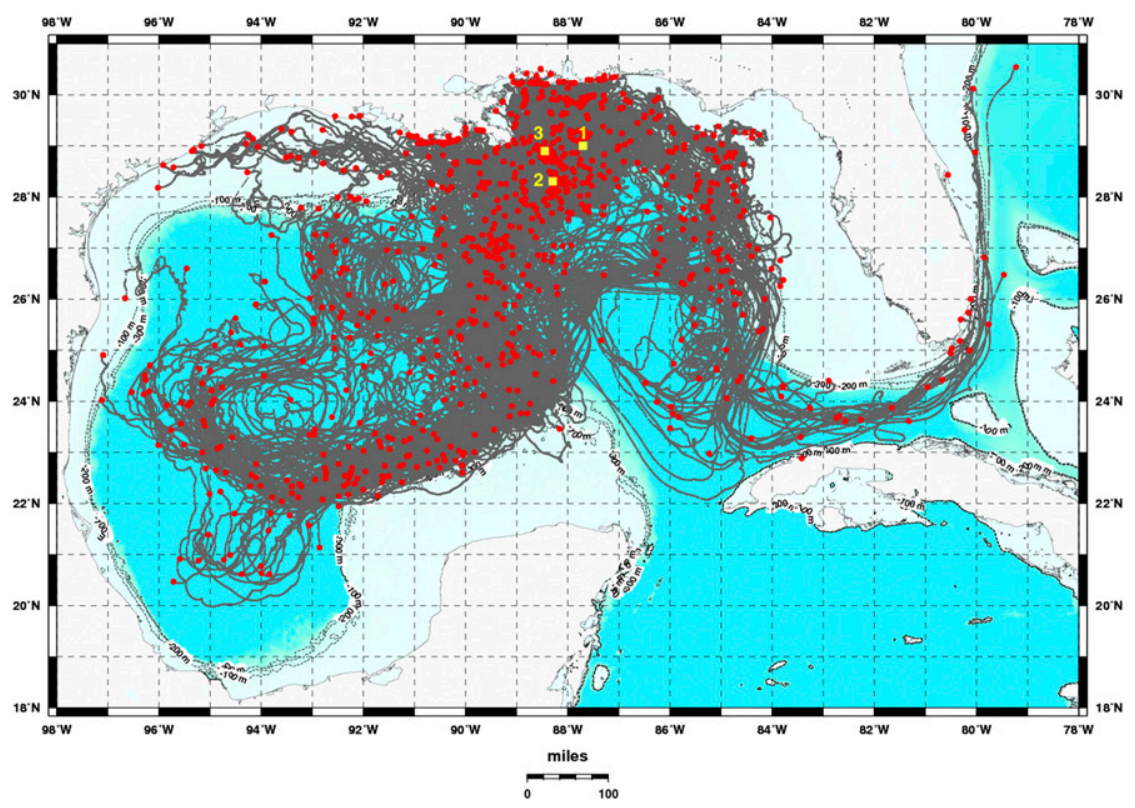

FIG. 21. Cumulative map of CARTHE drifters trajectories in the Gulf of Mexico as of $13 \mathrm{Apr}$ 2016. The three locations (yellow squares) where large multiscale arrays of drifters have been released: 1) on 21 Jan (310 drifters), 2) on 27-31 Jan (200 drifters), and 3) on 7 Feb (330 drifters). The last known positions of the drifters on 13 Apr (red dots). The tails (gray lines) are up to 75 days long.

$10 \mathrm{~km} \times 10 \mathrm{~km}$ but expanding over time). In two occasions, both ships coordinated the simultaneous release of up to 150 pairs of drifters at various initial separation distances, ranging from 100 to $500 \mathrm{~m}$, in vast $(8 \mathrm{~km} \times$ $8 \mathrm{~km})$ and dense multiscale arrays, in only a few hours.

Over 10 million positions have been collected over the 3-month period following the initial drifter deployment. The cumulative map of the trajectories as of 13 April is plotted in Fig. 21. It shows how all the drifters released in the De Soto Canyon have spread all over the Gulf of Mexico, spanning $20^{\circ}$ longitude by $12^{\circ}$ latitude. Of these drifters, 840 were deployed in dense grids at the three locations highlighted by yellow squares. The remaining drifters were dropped as needed to provide a contextual map of the mesoscale during the operation. The drifters that ran aground on the coasts of Texas, Louisiana, and Alabama were collected. In the midst of the cruise, we detected that some drifters' GPS transmissions suffered high dropout rates in conjunction with an apparent downwind drift. These drifters were tracked: the drogue attachment point had broken off and the floaters had flipped upside down during the passage of severe storms, causing the loss of GPS signal. It led us to redesign the tether, and its anchoring points, inserting a steel chain through the rubber tubing that can resist stronger mechanical efforts in breaking waves. As anonymous reviewers of this manuscript pointed out, a drogue loss detection system, similar to the tether strain sensor used routinely in NOAA's Global Drifter Program (Lumpkin et al. 2013), could be a useful feature to add to the next version of the drifter to help discriminate between drifters with and without drogue. Since the drifting characteristics of both the floater and the drifter with its drogue have been determined already, the data from both drifters and floaters could be used, for instance, to compare the dispersion of surface and subsurface material.

The drifters have reported their positions every $5 \mathrm{~min}$ for over 3 months, with initial separations ranging from $100 \mathrm{~m}$ up to $10 \mathrm{~km}$. They have sampled well the submesoscale and the mesoscale in the Gulf of Mexico, drawing over time the contours of the prominent mesoscale features such as, for example, the loop current anticyclonic eddy centered near $25^{\circ} \mathrm{N}, 87^{\circ} \mathrm{W}$ and an associated cyclonic eddy centered near $27^{\circ} \mathrm{N}, 86^{\circ} \mathrm{W}$, along with two large anticyclonic eddies in the western Gulf at $24^{\circ} \mathrm{N}, 94^{\circ} \mathrm{W}$ and $26^{\circ} \mathrm{N}, 91^{\circ} \mathrm{W}$.

\section{Conclusions}

The CARTHE surface drifter design was developed to be compact, scalable, and cost effective to manufacture and operate. The drifter was composed of a biodegradable biopolymer ( $85 \%$ ) and nontoxic electronics $(15 \%)$ of its mass, in order to reduce its environmental footprint in case the drifter could not be recovered. It is 
intended to accurately follow the current over the upper $0.60 \mathrm{~m}$, with very limited influence from the wind or waves. Its behavior under waves and winds was investigated in a series of laboratory and field experiments. The first major finding from the laboratory experiment is that short steep waves could induce a resonant oscillatory response on rigid vertical surface drifters that lead them to move much faster than the real flow. As a result, the CARTHE drifter uses a flexible tether to link the floater and the drogue to reduce significantly the wave rectification issues. The second result from the wind flume experiment is that the torus shape of the floater has a low windage, in particular at high wind speed, when the low profile torus is positioned in the wake of the steep waves' crests. In the wind flume, for $U_{10}=8.1$ $\mathrm{m} \mathrm{s}^{-1}$, the drifter slip velocity with drogue was less than $0.5 \%$ of $U_{10}$ and without drogue, the slip velocity reaches $2 \%$ of $U_{10}$. In coastal and deep ocean deployments, under a variety of current, strong wind, and wave conditions, the CARTHE and CODE drifters' trajectories were nearly identical for deployments lasting up to 6 days over hundreds of kilometers. The drifter design facilitated the manufacturing and successful deployment of more than 1000 units, each one providing highspatial- and high-temporal-resolution measurements of the surface velocity field during LASER.

The compactness of the CARTHE drifter is well adapted as well for conducting research from small boats (or even from shore) in shallow coastal areas such as harbors but also lakes, rivers, and estuaries. Its biodegradability and low toxicity makes it suitable for studying marine protected areas and pristine environments such as the Arctic, especially if drifters are not to be collected after the experiment is over.

Acknowledgments. This research was made possible by the Gulf of Mexico Research Initiative (Grant SA-1515 CARTHE). Data are publicly available through the Gulf of Mexico Research Initiative Information and Data Cooperative (GRIIDC) (at https://data.gulfresearchinitiative. org/; doi:10.7266/N7VH5KWX). We are grateful to the editor and to three anonymous reviewers for their comments and suggestions, which greatly improved the manuscript.

\section{REFERENCES}

Andrady, A. L., 2015: Persistence of plastic litter in the oceans. Marine Anthropogenic Litter, M. Bergmann, L. Gutow, and M. Klages, Eds., Springer, 57-72, https://doi.org/10.1007/ 978-3-319-16510-3_3.

Berta, M., A. Griffa, M. G. Magaldi, T. M. Özgökmen, A. C. Poje, A. C. Haza, and M. J. Olascoaga, 2015: Improved surface velocity and trajectory estimates in the Gulf of Mexico from blended satellite altimetry and drifter data. J. Atmos. Oceanic Technol., 32, 1880-1901, https://doi.org/10.1175/JTECH-D-14-00226.1.

,,-- T. M. Özgökmen, and A. C. Poje, 2016: Submesoscale evolution of surface drifter triads in the Gulf of Mexico. Geophys. Res. Lett., 43, 11 751-11 759, https://doi.org/10.1002/ 2016 GL070357.

Boccaletti, G., R. Ferrari, and B. Fox-Kemper, 2007: Mixed layer instabilities and restratification. J. Phys. Oceanogr., 37, 2228-2250, https://doi.org/10.1175/JPO3101.1.

Buckley, M. P., and F. Veron, 2016: Structure of the airflow above surface waves. J. Phys. Oceanogr., 46, 1377-1397, https://doi.org/ 10.1175/JPO-D-15-0135.1.

Chavanne, C. P., and P. Klein, 2010: Can oceanic submesoscale processes be observed with satellite altimetry? Geophys. Res. Lett., 37, L22602, https://doi.org/10.1029/2010GL045057.

Cózar, A., and Coauthors, 2014: Plastic debris in the open ocean. Proc. Natl. Acad. Sci. USA, 111, 10 239-10244, https://doi.org/ 10.1073/pnas.1314705111.

Curcic, M., S. S. Chen, and T. M. Özgökmen, 2016: Hurricaneinduced ocean waves and stokes drift and their impacts on surface transport and dispersion in the Gulf of Mexico. Geophys. Res. Lett., 43, 2773-2781, https://doi.org/10.1002/ 2015 GL067619.

D’Asaro, E., C. Lee, L. Rainville, R. Harcourt, and L. Thomas, 2011: Enhanced turbulence and energy dissipation at ocean fronts. Science, 332, 318-322, https://doi.org/10.1126/ science.1201515.

Davis, R. E., 1985a: Drifter observations of coastal surface currents during CODE: The method and descriptive view. J. Geophys. Res., 90, 4741-4755, https://doi.org/10.1029/JC090iC03p04741.

_ 1985b: Drifter observations of coastal surface currents during CODE: The statistical and dynamical views. J. Geophys. Res., 90, 4756-4772, https://doi.org/10.1029/JC090iC03p04756.

_ 1991a: Lagrangian ocean studies. Annu. Rev. Fluid Mech., 23, 43-64, https://doi.org/10.1146/annurev.fl.23.010191.000355.

_ 1991b: Observing the general circulation with floats. DeepSea Res., 38A, S531-S571, https://doi.org/10.1016/S0198-0149 (12)80023-9.

DiGregorio, B. E., 2009: Biobased performance bioplastic: Mirel. Chem. Biol., 16, 1-2, https://doi.org/10.1016/ j.chembiol.2009.01.001.

Donelan, M. A., B. K. Haus, N. Reul, W. J. Plant, M. Stiassnie, H. C. Graber, O. B. Brown, and E. S. Saltzman, 2004: On the limiting aerodynamic roughness of the ocean in very strong winds. Geophys. Res. Lett., 31, L18306, https://doi.org/10.1029/ $2004 \mathrm{gl} 1019460$.

Fu, L.-L., and R. Ferrari, 2008: Observing oceanic submesoscale processes from space. Eos, Trans. Amer. Geophys. Union, 89, 488-489, https://doi.org/10.1029/2008EO480003.

GESAMP, 2015: Sources, fate and effects of microplastics in the marine environment: A global assessment. GESAMP Reports and Studies 90, $96 \mathrm{pp}$.

Geyer, R., 1989: Field calibration of mixed layer drifters. J. Atmos. Oceanic Technol., 6, 333-342, https://doi.org/ 10.1175/1520-0426(1989)006<0333:FCOMLD > 2.0.CO;2.

Gildor, H., E. Fredj, J. Steinbuck, and S. Monismith, 2009: Evidence for submesoscale barriers to horizontal mixing in the ocean from current measurements and aerial photographs. J. Phys. Oceanogr., 39, 1975-1983, https://doi.org/10.1175/ 2009JPO4116.1.

Gregory, M. R., 2009: Environmental implications of plastic debris in marine settings-Entanglement, ingestion, smothering, hangers-on, hitch-hiking and alien invasions. Philos. Trans. 
Roy. Soc. London, 364B, 2013-2025, https://doi.org/10.1098/ rstb.2008.0265.

Haza, A. C., T. M. Özgökmen, A. Griffa, A. C. Poje, and M.-P. Lelong, 2014: How does drifter position uncertainty affect ocean dispersion estimates? J. Atmos. Oceanic Technol., 31, 2809-2828, https://doi.org/10.1175/JTECH-D-14-00107.1.

Huntley, H. S., B. Lipphardt Jr., G. Jacobs, and A. Kirwan Jr., 2015: Clusters, deformation, and dilation: Diagnostics for material accumulation regions. J. Geophys. Res. Oceans, 120, 6622-6636, https://doi.org/10.1002/2015JC011036.

Jacobs, G. A., H. S. Huntley, A. D. Kirwan Jr., B. L. Lipphardt Jr., T. Campbell, T. Smith, K. Edwards, and B. Bartels, 2016: Ocean processes underlying surface clustering. J. Geophys. Res. Oceans, 121, 180-197, https://doi.org/10.1002/ 2015JC011140.

Jones, C. E., B. Minchew, B. Holt, and S. Hensley, 2010: Studies of the Deepwater Horizon oil spill with the UAVSAR radar. Monitoring and Modeling the Deepwater Horizon Oil Spill: A Record-Breaking Enterprise, Geophys. Monogr., Vol. 195, Amer. Geophys. Union, 33-50, https://doi.org/10.1029/ 2011GM001113.

_ - and Coauthors, 2016: Measurement and modeling of oil slick transport. J. Geophys. Res. Oceans, 121, 7759-7775, doi:10.1002/2016JC012113.

Klein, P., and G. Lapeyre, 2009: The oceanic vertical pump induced by mesoscale and submesoscale turbulence. Annu. Rev. Mar. Sci., 1, 351-375, https://doi.org/10.1146/annurev.marine.010908.163704.

Koszalka, I., J. H. LaCasce, and K. A. Orvik, 2009: Relative dispersion in the Nordic Seas. J. Mar. Res., 67, 411-433, https:// doi.org/10.1357/002224009790741102.

LaCasce, J. H., 2008: Statistics from Lagrangian observations. Prog. Oceanogr., 77, 1-29, https://doi.org/10.1016/j.pocean.2008.02.002.

_ and J. C. Ohlmann, 2003: Relative dispersion at the surface of the Gulf of Mexico. J. Mar. Res., 61, 285-312, https://doi.org/ 10.1357/002224003322201205.

Langmuir, I., 1938: Surface motion of water induced by wind. Science, 87, 119-123, https://doi.org/10.1126/science.87.2250.119.

Law, K. L., 2010: Plastic accumulation in the North Atlantic Subtropical Gyre. Science, 329, 1185-1188, https://doi.org/10.1126/ science.1192321.

Lévy, M., R. Ferrari, P. J. S. Franks, A. P. Martin, and P. Rivière, 2012: Bringing physics to life at the submesoscale. Geophys. Res. Lett., 39, L14602, https://doi.og/10.1029/2012GL052756.

Lumpkin, R., and M. Pazos, 2007: Measuring surface currents with Surface Velocity Program drifters: The instrument, its data, and some recent results. Lagrangian Analysis and Prediction of Coastal and Ocean Dynamics, A. Griffa et al., Eds., Cambridge University Press, 39-67, https://doi.org/10.1017/ CBO9780511535901.003.

— North Atlantic. J. Geophys. Res., 115, C12017, https://doi.org/ 10.1029/2010JC006338.

—, S. A. Grodsky, L. Centurioni, M.-H. Rio, J. A. Carton, and D. Lee, 2013: Removing spurious low-frequency variability in drifter velocities. J. Atmos. Oceanic Technol., 30, 353-360, https://doi.org/10.1175/JTECH-D-12-00139.1.

— T. M. Özgökmen, and L. Centurioni, 2017: Advances in the application of surface drifters. Annu. Rev. Mar. Sci., 9, 59-81, https://doi.org/10.1146/annurev-marine-010816-060641.

MacMahan, J., J. Brown, and E. Thornton, 2009: Low-cost handheld global positioning system for measuring surf-zone currents. J. Coastal Res., 253, 744-754, https://doi.org/ 10.2112/08-1000.1.
Mariano, A. J., and Coauthors, 2016: Statistical properties of the surface velocity field in the northern Gulf of Mexico sampled by GLAD drifters. J. Geophys. Res. Oceans, 121, 5193-5216, https://doi.org/10.1002/2015JC011569.

Maximenko, N., R. Lumpkin, and L. Centurioni, 2013: Ocean surface circulation. Ocean Circulation and Climate: A 21st Century Perspective, G. Siedler et al., Eds., International Geophysics Series, Vol. 103, Academic Press, 283-300.

McWilliams, J. C., 2008: Fluid dynamics at the margin of rotational control. Environ. Fluid Mech., 8, 441-449, https://doi.org/ 10.1007/s10652-008-9081-8.

, 2016: Submesoscale currents in the ocean. Proc. Roy. Soc. London, 472A, 20160117, https://doi.org/10.1098/rspa.2016.0117.

Mensa, J., Z. Garraffo, A. Griffa, T. M. Özgökmen, A. Haza, and M. Veneziani, 2013: Seasonality of the submesoscale dynamics in the Gulf Stream region. Ocean Dyn., 63, 923-941, https:// doi.org/10.1007/s10236-013-0633-1.

Monismith, S. G., E. A. Cowen, H. M. Nepf, J. Magnaudet, and L. Thais, 2007: Laboratory observations of mean flows under surface gravity waves. J. Fluid Mech., 573, 131-147, https:// doi.org/10.1017/S0022112006003594.

Moore, C. J., 2008: Synthetic polymers in the marine environment: A rapidly increasing, long-term threat. Environ. Res., 108, 131-139, https://doi.org/10.1016/j.envres.2008.07.025.

Mullaney, T. J., and I. M. Suthers, 2013: Entrainment and retention of the coastal larval fish assemblage by a short-lived, submesoscale, frontal eddy of the East Australian Current. Limnol. Oceanogr., 58, 1546-1556, https://doi.org/10.4319/ lo.2013.58.5.1546

Müller, P., J. C. McWilliams, and M. J. Molemaker, 2005: Routes to dissipation in the ocean: The $2 \mathrm{D} / 3 \mathrm{D}$ turbulence conundrum. Marine Turbulence: Theories, Observations, and Models. Results of the CARTUM Project, H. Baumert, J. Simpson, and J. Sündermann, Eds., Cambridge University Press, 1-23.

Munk, W., L. Armi, K. Fischer, and F. Zachariasen, 2000: Spirals on the sea. Proc. Roy. Soc. London, 456A, 1217-1280, https:// doi.org/10.1098/rspa.2000.0560.

Niller, P. P., R. E. Davis, and H. J. White, 1987: Water-following characteristics of a mixed layer drifter. Deep-Sea Res., 34A, 1867-1881, https://doi.org/10.1016/0198-0149(87)90060-4.

Niiler, P. P., A. S. Sybrandy, K. Bi, P. M. Poulain, and D. Bitterman, 1995: Measurements of the water-following capability of holey-sock and TRISTAR drifters. Deep-Sea Res. I, 42, https://doi.org/10.1016/0967-0637(95)00076-3.

Ohlmann, J. C., and P. P. Niiler, 2001: A two-dimensional response to a tropical storm on the Gulf of Mexico shelf. J. Mar. Syst., 29, 87-99, https://doi.org/10.1016/S0924-7963(01)00011-2.

, and - 2005: Circulation over the continental shelf in the northern Gulf of Mexico. Prog. Oceanogr., 64, 45-81, https:// doi.org/10.1016/j.pocean.2005.02.001.

, — , C. A. Fox, and R. R. Leben, 2001: Eddy energy and shelf interactions in the Gulf of Mexico. J. Geophys. Res., 106, 2605-2620, https://doi.org/10.1029/1999JC000162.

_ P. F. White, A. L. Sybrandy, and P. P. Niiler, 2005: GPScellular drifter technology for coastal ocean observing systems. J. Atmos. Oceanic Technol., 22, 1381-1388, https:// doi.org/10.1175/JTECH1786.1.

Olascoaga, M. J., and Coauthors, 2013: Drifter motion in the Gulf of Mexico constrained by altimetric Lagrangian coherent structures. Geophys. Res. Lett., 40, 6171-6175, https://doi.org/ 10.1002/2013GL058624.

Özgökmen, T. M., and P. F. Fischer, 2012: CFD application to oceanic mixed layer sampling with Lagrangian platforms. 
Int. J. Comput. Fluid Dyn., 26, 337-348, https://doi.org/ 10.1080/10618562.2012.668888.

- A. C. Poje, P. F. Fischer, and A. C. Haza, 2011: Large eddy simulations of mixed layer instabilities and sampling strategies. Ocean Modell., 39, 311-331, https://doi.org/10.1016/ j.ocemod.2011.05.006.

,,-- H. Childs, H. Krishnan, C. Garth, A. C. Haza, and E. Ryan, 2012: On multi-scale dispersion under the influence of surface mixed layer instabilities and deep flows. Ocean Modell., 56, 16-30, https://doi.org/10.1016/j.ocemod.2012.07.004.

Pearman, D. W., T. H. C. Herbers, T. T. Janssen, H. D. van Ettinger, S. A. McIntyre, and P. F. Jessen, 2014: Drifter observations of the effects of shoals and tidal-currents on wave evolution in San Francisco Bight. Cont. Shelf Res., 91, 109-119, https://doi.org/10.1016/j.csr.2014.08.011.

Phillips, O. M., 1977: The Dynamics of the Upper Ocean. Cambridge University Press, $336 \mathrm{pp}$.

Poje, A. C., and Coauthors, 2014: Submesoscale dispersion in the vicinity of the Deepwater Horizon spill. Proc. Natl. Acad. Sci. USA, 111, 12 693-12 698, https://doi.org/10.1073/ pnas. 1402452111.

_, T. M. Özgökmen, D. J. Bogucki, and J. A. D. Kirwan, 2017: Evidence of a forward energy cascade and Kolmogorov selfsimilarity in submesoscale ocean surface drifter observations. Phys. Fluids, 29, 020701, https://doi.org/10.1063/1.4974331.

Poulain, P.-M., 1999: Drifter observations of surface circulation in the Adriatic Sea between December 1994 and March 1996. J. Mar. Syst., 20, 231-253, https://doi.org/10.1016/ S0924-7963(98)00084-0.

, and E. Zambianchi, 2007: Surface circulation in the central Mediterranean Sea as deduced from Lagrangian drifters in the 1990s. Cont. Shelf Res., 27, 981-1001, https://doi.org/ 10.1016/j.csr.2007.01.005.

_, L. Ursella, and F. Brunetti, 2002: Direct measurements of water-following characteristics of CODE surface drifters. Second Lagrangian Analysis and Prediction of Coastal and Ocean Dynamics (LAPCOD) Meeting, Key Largo, FL, Office of Naval Research, C302, http://www.rsmas.miami.edu/ LAPCOD/2002-KeyLargo/abstracts/absC302.html.

—, A. Bassani, R. Gerin, R. Jungwirth, E. Mauri, M. Menna, and G. Notarstefano, 2013: Mediterranean surface currents measured with drifters: From basin to subinertial scales. Oceanography, 26, 38-47, https://doi.org/10.5670/oceanog.2013.03.

Reddy, C. S. K., R. Ghai, and V. C. Kalia, 2003: Polyhydroxyalkanoates: An overview. Bioresour. Technol., 87, 137-146, https://doi.org/10.1016/S0960-8524(02)00212-2.

Reed, M., C. Turner, and A. Odulo, 1994: The role of wind and emulsification in modelling oil spill and surface drifter trajectories. Spill Sci. Technol. Bull., 1, 143-157, https://doi.org/ 10.1016/1353-2561(94)90022-1.

Röhrs, J., and K. H. Christensen, 2015: Drift in the uppermost part of the ocean. Geophys. Res. Lett., 42, 10349-10356, https:// doi.org/10.1002/2015GL066733.

,,- L. R. Hole, G. Broström, M. Drivdal, and S. Sundby, 2012: Observation-based evaluation of surface wave effects on currents and trajectory forecasts. Ocean Dyn., 62, 1519-1533, https://doi.org/10.1007/s10236-012-0576-y.

Schroeder, K., A. C. Haza, A. Griffa, T. M. Özgökmen, P. M. Poulain, R. Gerin, G. Peggion, and M. Rixen, 2011: Relative dispersion in the Liguro-Provençal basin: From sub-mesoscale to mesoscale. Deep-Sea Res. I, 58, 209-228, https://doi.org/ 10.1016/j.dsr.2010.11.004.

, and Coauthors, 2012: Targeted Lagrangian sampling of submesoscale dispersion at a coastal frontal zone. Geophys. Res. Lett., 39, L11608, https://doi.org/10.1029/2012GL051879.

Shay, L. K., and Coauthors, 2000: VHF radar detects oceanic submesoscale vortex along Florida Coast. Eos, Trans. Amer. Geophys. Union, 81, 209-213, https://doi.org/10.1029/ 00EO00143.

Shcherbina, A. Y., E. A. D. Asaro, C. M. Lee, J. M. Klymak, M. J. Molemaker, and J. C. McWilliams, 2013: Statistics of vertical vorticity, divergence, and strain in a developed submesoscale turbulence field. Geophys. Res. Lett., 40, 4706-4711, https:// doi.org/10.1002/grl.50919.

Smith, S. D., 1988: Coefficients for sea surface wind stress, heat flux, and wind profiles as a function of wind speed and temperature. J. Geophys. Res., 93, 15 467-15 472, https://doi.org/10.1029/ JC093iC12p15467.

Stokes, G. G., 1847: On the theory of oscillatory waves. Trans. Cambridge Philos. Soc., 8, 441-455.

Sundermeyer, M., and J. Ledwell, 2001: Lateral dispersion over the continental shelf: Analysis of dye release experiments. J. Geophys. Res., 106, 9603-9621, https://doi.org/10.1029/ 2000JC900138.

Thomas, L. N., A. Tandon, and A. Mahadevan, 2008: Submesoscale processes and dynamics. Ocean Modeling in an Eddying Regime, M. W. Hecht and H. Hasumi, Eds., Wiley, 17-38, https://doi.org/10.1029/177GM04.

Thorpe, S. A., 2004: Langmuir circulation. Annu. Rev. Fluid Mech., 36, 55-79, https://doi.org/10.1146/annurev.fluid.36.052203.071431.

Webb, A., and B. Fox-Kemper, 2011: Wave spectral moments and Stokes drift estimation. Ocean Modell., 40, 273-288, https:// doi.org/10.1016/j.ocemod.2011.08.007.

- , and - 2015: Impacts of wave spreading and multidirectional waves on estimating Stokes drift. Ocean Modell., 96, 49-64, https://doi.org/10.1016/j.ocemod.2014.12.007.

Wilcox, C., E. Van Sebille, and B. D. Hardesty, 2015: Threat of plastic pollution to seabirds is global, pervasive, and increasing. Proc. Natl. Acad. Sci. USA, 112, 11899-11904, https://doi.org/10.1073/pnas.1502108112.

Wu, J., 1975: Wind-induced drift currents. J. Fluid Mech., 68, 49-70, https://doi.org/10.1017/S0022112075000687.

Zhong, Y., A. Bracco, and T. A. Villareal, 2012: Pattern formation at the ocean surface: Sargassum distribution and the role of the eddy field. Limnol. Oceanogr. Fluids Environ., 2, 12-27, https://doi.org/10.1215/21573689-1573372.

Zhurbas, V., and I. S. Oh, 2004: Drifter-derived maps of lateral diffusivity in the Pacific and Atlantic Oceans in relation to surface circulation patterns. J. Geophys. Res., 109, C05015, https://doi.org/10.1029/2003JC002241. 